\title{
Review of Research on the Rare-Earth Doped Piezoelectric Materials
}

\author{
Yan Chen, Donglai Zhang, Zhong Peng, Maodan Yuan* and Xuanrong Ji * \\ State Key Laboratory of Precision Electronics Manufacturing Technology and Equipment, Guangdong University of Technology, \\ Guangzhou, China
}

The piezoelectric materials, such as ceramics, crystals, and films, have wide applications in the mechanical industry, medical imaging, electronic information, and ultrasonic devices, etc. Generally, adding oxide dopants, or introducing new solid solutions to form the morphotropic phase boundary of the piezoelectric materials were common strategies to enhance the electric properties. In recent decades, rare-earth elements doped piezoelectric materials have attracted much attention due to their multifunctional performances combining piezoelectric and photoluminescence properties, which has potential applications in ultrasonics, electronics, automatic control, machinery and optoelectronic fields. An overview of the recent investigations and perspectives on rare-earth doped piezoelectric ceramics, single crystals, and films were presented.

\section{OPEN ACCESS}

Edited by:

Chunlong Fei,

Xidian University, China

Reviewed by:

Yi Quan,

Xi'an Jiaotong University, China Tian-Long Zhao,

Xidian University, China

${ }^{*}$ Correspondence:

Xuanrong Ji

xr.j@gdut.edu.cn

Maodan Yuan

mdyuan@gdut.edu.cn

Specialty section:

This article was submitted to

Smart Materials,

a section of the journal

Frontiers in Materials

Received: 11 March 2021

Accepted: 24 May 2021

Published: 08 July 2021

Citation:

Chen Y, Zhang D, Peng Z, Yuan M and JiX (2021) Review of Research on the Rare-Earth Doped

Piezoelectric Materials.

Front. Mater. 8:679167.

doi: $10.3389 /$ fmats.2021.679167
Keywords: piezoelectric materials, rare-earth doping, electric properties, photoluminescence properties, multifunctional materials

\section{INTRODUCTION}

Rare-earth (RE) elements contain rich structures and energy levels and exhibit excellent optical, electrical, magnetic, and nuclear properties, which were exploited in functional materials to enhance their properties and broaden applications (Singh et al., 2015; Steudel et al., 2015).

As one of the important functional materials, piezoelectric materials play a significant role in the fields of medicine, acoustics, machinery, and electronics due to the ability of mutual conversion between mechanical energy and electric energy. The electric performances of piezoelectric materials are affected by compositions, microstructure, and lattice defects like oxygen vacancies. Thus, extensive investigations have been carried out to enhance the properties of the piezoelectric materials by introducing new solid solutions or adding oxide dopants. The rare-earth ion doping may substitute the original ions and cause the formation of vacancies so that the distortion of the crystal lattices may affect the electric properties due to their unique ionic radius and different chemical valence (Qiu and Hng, 2002; Hagemann and Hennings, 2010; Singh et al., 2011). There are 17 members in the family of rare-earth elements, including 15 lanthanides ( $\mathrm{La}, \mathrm{Ce}, \mathrm{Pr}, \mathrm{Nd}, \mathrm{Pm}, \mathrm{Sm}, \mathrm{Eu}, \mathrm{Gd}, \mathrm{Tb}, \mathrm{Dy}, \mathrm{Ho}, \mathrm{Er}, \mathrm{Tm}, \mathrm{Yb}, \mathrm{Lu}$ ), Sc, and Y. Figure 1 shows the rare-earth elements doped piezoelectric materials and relative properties based on the reported works. Some piezoelectric materials with certain rare-earth doping can exhibit obvious photoluminescence properties because of the ladder-shaped $4 \mathrm{f}$ energy level and relatively long metastable state of some rare-earth ions (Tsonev, 2008; Sun et al., 2011; Pieter, 2013; Pieter, 2017). Figure $2 \mathrm{~A}$ shows the main energy flow paths during the sensitization of lanthanide (Ln) luminescence. The energy levels of $\mathrm{Pr}^{3+}, \mathrm{Nd}^{3+}, \mathrm{Sm}^{3+}, \mathrm{Eu}^{3+}, \mathrm{Tb}^{3+}, \mathrm{Dy}^{3+}, \mathrm{Ho}^{3+}, \mathrm{Er}^{3+}, \mathrm{Tm}^{3+}$, and $\mathrm{Yb}^{3+}$ ions are also given schematically in Figure 2B. The electrons in the singlet $\left(\mathrm{S}_{0}\right)$ ground state absorb energy and then jump to the singlet (S1) excited state. Besides, the excitation energy of $\left(\mathrm{S}_{1}\right)$ state is transferred to the triplet state $(\mathrm{T})$ based on intersystem crossing firstly and to the $4 \mathrm{f}$ states 


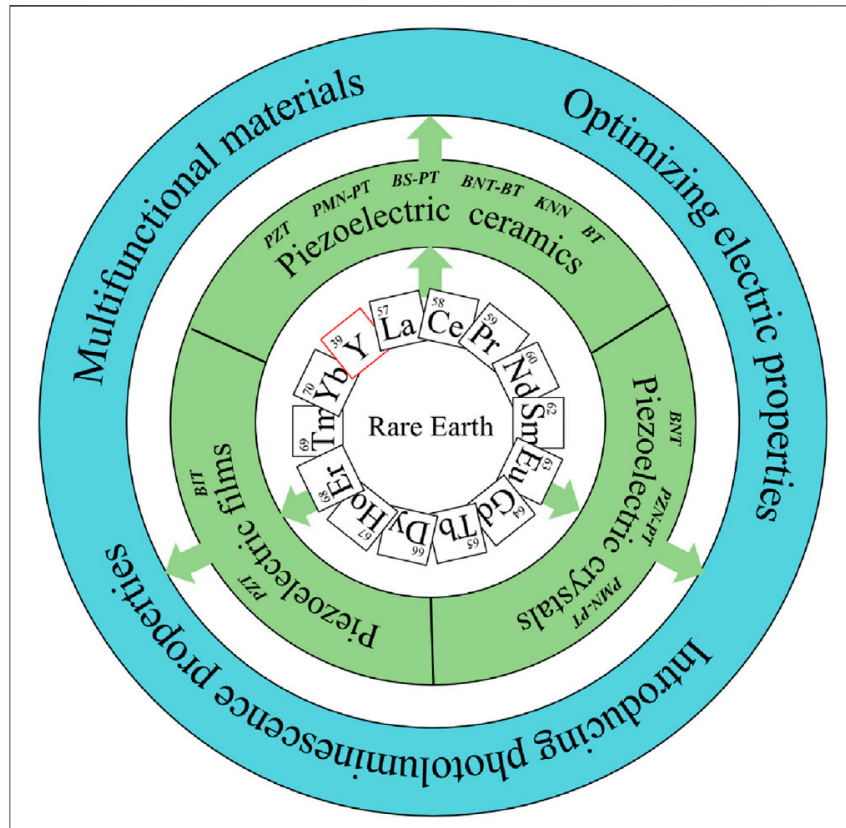

FIGURE 1 | Relationship between the rare Earth, piezoelectric materials, and properties.

subsequently. Finally, the corresponding emission of lanthanide ions can be acquired (Sun et al., 2006; Dang et al., 2008).

Although the rare-earth ion doped piezoelectric materials have attracted much attention owing to their outstanding electric and luminescence performance, there are few reviews reported in this research field. Most reviews are focused on a certain type of piezoelectric material or a fabricating method. Zheng et al. (2018) addressed the lead-free perovskite piezoelectric bulk materials. The relationships among the phase boundaries, domain configurations, and electrical properties in lead-free materials were discussed. Liu (2015) reviewed the progress on lead-free textured piezoelectric ceramics with an enhancement of the piezoelectric property. Chen et al. (2020a) paid attention to the progress of piezoelectric materials fabricated by additive manufacturing. In this paper, the effect of rare-earth doping on the electrical and optical properties of piezoelectric ceramics, crystals, and films are reviewed and discussed.

\section{RARE-EARTH DOPED PIEZOELECTRIC CERAMICS}

\section{Rare-Earth Doped Lead-Based Piezoelectric Ceramics}

Piezoelectric ceramics are a kind of piezoelectric materials with a wide range of applications due to the characteristics of good electric properties, fine optical properties, low production cost, and simple preparation. In the past few decades, lead-based piezoelectric ceramics have dominated the market due to their good properties. In the following section, the rare-earth doped lead-based ceramics were summarized.

\section{Rare-Earth Doped PZT-Based Ceramics}

$\mathrm{Pb}\left(\mathrm{Zr}_{\mathrm{x}} \mathrm{Ti}_{1-\mathrm{x}}\right) \mathrm{O}_{3}(\mathrm{PZT})$ ceramics are the most studied and applied piezoelectric material. The piezoelectric constant $\mathrm{d}_{33}$ and Curie temperature $\mathrm{T}_{\mathrm{c}}$ of PZT-5A ceramics can reach $375 \mathrm{pC} / \mathrm{N}$ and $365^{\circ} \mathrm{C}$, respectively (Shrout and Zhang, 2007; Chen et al., 2018).

Shannigrahi et al. (2004) synthesized the PZT (60/40) ceramics doped with rare-earth (La, Nd, Sm, Eu, Gd, Dy, and Er) by sol-gel growth. Among them, the ceramic doped with La has the largest dielectric constant $\varepsilon_{\mathrm{r}}$ of 3,413 , and the piezoelectric constant $\mathrm{d}_{33}$ and the remnant polarization $\mathrm{P}_{\mathrm{r}}$ can reach $569 \mathrm{pC} / \mathrm{N}$ and $21.9 \mu \mathrm{C} / \mathrm{cm}^{2}$, respectively. Nevertheless, the Curie temperature $\mathrm{T}_{\mathrm{c}}$ was lowest $\left(\sim 156^{\circ} \mathrm{C}\right)$. The Dy doped ceramic has the highest Curie temperature $\mathrm{T}_{\mathrm{c}}$ of $368^{\circ} \mathrm{C}$. Khazanchi et al. (2005) reported Eu doped PZT (55/45) ceramics. The dielectric constant $\varepsilon_{\mathrm{r}}$ and the remnant polarization $\mathrm{P}_{\mathrm{r}}$ of $2 \mathrm{~mol} \%$ Eu doped samples increased to 1,132 and $26.05 \mu \mathrm{C} / \mathrm{cm}^{2}$, respectively. Pandey et al. (2009) developed Sm doped PZT (65/35) ceramics showing good electric properties, and the dielectric constant $\varepsilon_{\mathrm{r}}$, the piezoelectric constant $\mathrm{d}_{33}$ and the planar electromechanical coupling coefficient $\mathrm{k}_{\mathrm{p}}$ of the $6 \mathrm{~mol} \% \mathrm{Sm}$ doped ceramic increased to $610,172 \mathrm{pC} / \mathrm{N}$, and 0.42 , respectively. Perumal et al. (2019) reported that the $\mathrm{Nd}$ doped PZT (52/48) has good electrical properties (149 pC/N) and low conductivity $\left(\sim 10^{-3} \mathrm{~S} / \mathrm{m}\right)$. Guo et al. (2020) achieved Yb doped PZT based ceramics with good electric properties. The piezoelectric constant $d_{33}$, planar electromechanical coupling coefficient $\mathrm{k}_{\mathrm{p}}$, and the dielectric constant $\varepsilon_{\mathrm{r}}$ of the ceramics can reach $308 \mathrm{pC} / \mathrm{N}, 0.57$, and 1,210, respectively. Kour et al. (2015) and Kour et al. (2016) reported that the piezoelectric constant $\mathrm{d}_{33}$ of the PZT ceramics with $10 \mathrm{~mol} \% \mathrm{La}$ doping was $381 \mathrm{pC} / \mathrm{N}$. In conclusion, the rare-earth doped PZT ceramics exhibit good piezoelectric properties which are suitable for general applications, including sensors, actuators, and ultrasound transducers.

Except for the enhancement of electric performance after rareearth doping, the optical properties also varied significantly. Ladoped PZT (PLZT) transparent ceramics have also attracted great attention in fundamental research as well as in applications due to a wide variety of optical properties. Zhang et al. (2006) observed three emission peaks at $915,1,066$, and $1,347 \mathrm{~nm}$ in the $\mathrm{Nd}$ doped PLZT ceramics under the excitation of a continuous wave diode laser. Zeng et al. (2014) prepared the Dy doped PLZT ceramics by hot-pressing sintering. It was shown that the Dy substituting decreased the coercive field $\mathrm{E}_{\mathcal{c}}$, but improved the optical transmittance and electro-optic effect. Especially, the transparency can reach as high as $67 \%$ at $632.8 \mathrm{~nm}$. Zhao et al. (2014) reported that the intensity of the emission peak $(1800 \mathrm{~nm})$ in Tm doped PLZT ceramics was obvious and strong, while the emission intensity reduced when doped with Ho. Strikingly, a quite strong emission at 1900-2200 nm emerged, whose full width at half maxima (FWHM) was up to $200 \mathrm{~nm}$, which indicated $\mathrm{Ho} / \mathrm{Tm}$ co-doped PLZT ceramics had potential application prospect in tunable lasers around $2000 \mathrm{~nm}$. Moreover, the structural and spectroscopic properties of $\mathrm{Nd}$, Er, Yb doped and co-doped PLZT ceramics were also studied as potential laser materials in the near infrared region (Camargo 


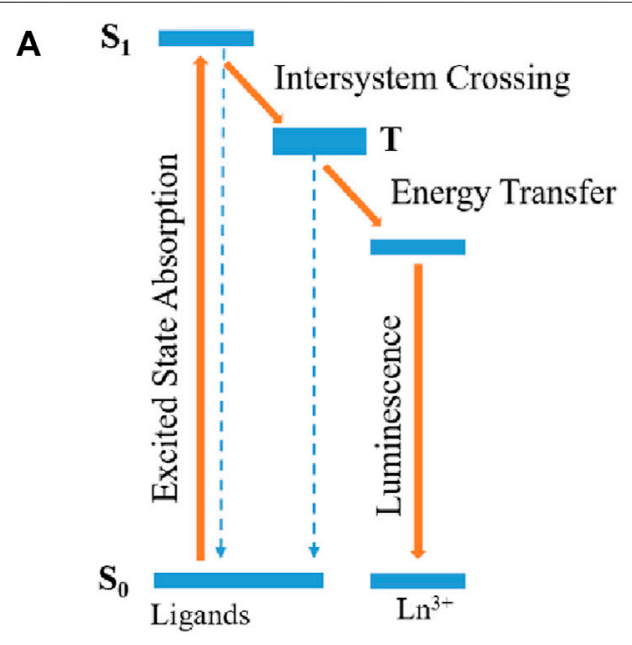

B
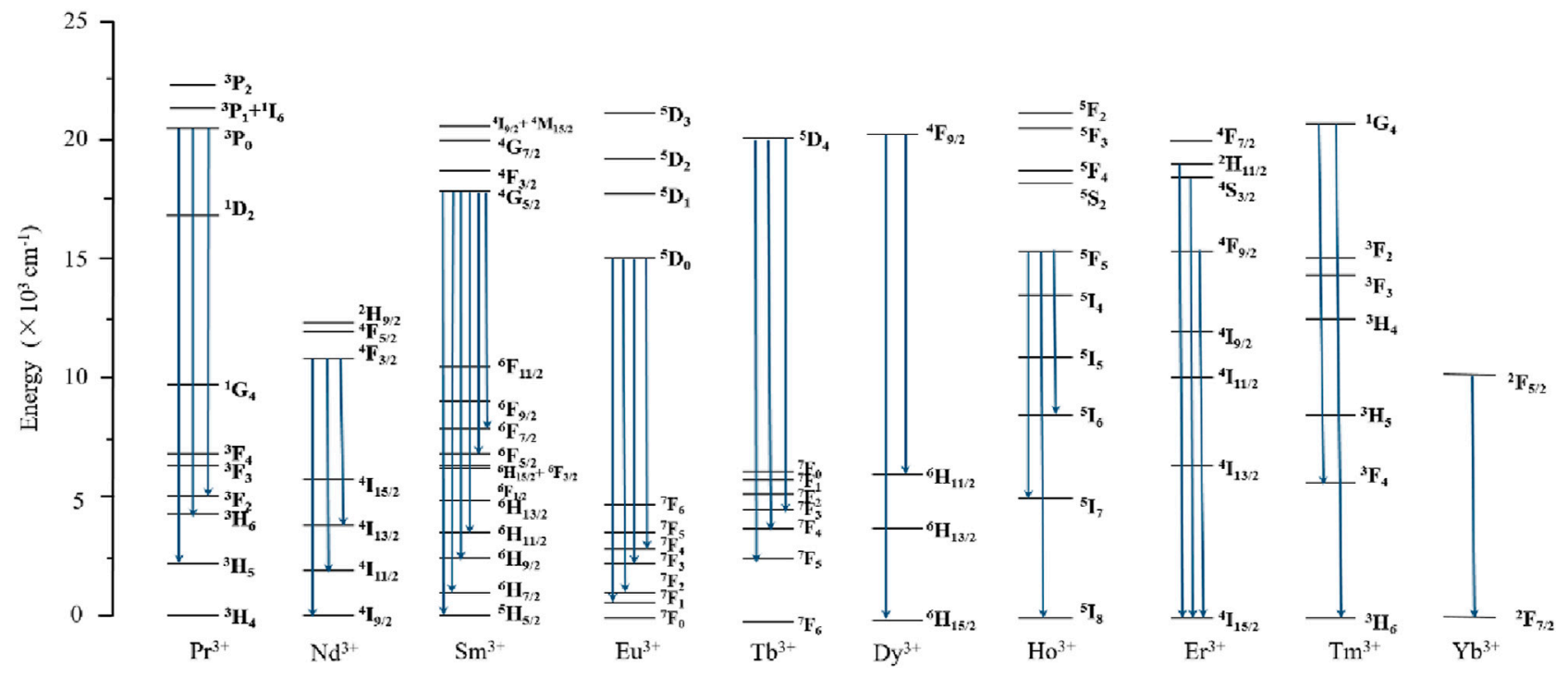

FIGURE 2 | (A) The diagram of the main energy flow paths during the sensitization of lanthanide luminescence via the ligands. (B) The diagram of the energy levels of $\mathrm{Pr}^{3+}, \mathrm{Nd}^{3+}, \mathrm{Sm}^{3+}, \mathrm{Eu}^{3+}, \mathrm{Tb}^{3+}, \mathrm{Dy}^{3+}, \mathrm{Ho}^{3+}, \mathrm{Er}^{3+}, \mathrm{Tm}^{3+}$, and $\mathrm{Yb}^{3+}$ ions.

et al., 2004; Camargo et al., 2005). These studies indicated that the transparent PLZT ceramics with rare-earth doping were suitable for photonic devices, optic sensors, and multifunctional optic devices, etc.

Furthermore, the $\mathrm{Pb}\left(\mathrm{Zn}_{1 / 3} \mathrm{Nb}_{2 / 3}\right) \mathrm{O}_{3}-\mathrm{Pb}\left(\mathrm{Zr}_{51} \mathrm{Ti}_{49}\right) \mathrm{O}_{3}$ ( $\mathrm{PZN}$ PZT) system has recently attracted much attention owing to their better piezoelectric properties $\left(\mathrm{d}_{33}=550 \mathrm{pC} / \mathrm{N}, \mathrm{k}_{\mathrm{p}}=0.69\right)$ compared with traditional PZT ceramics (Vittayakorn et al., 2006; Zheng et al., 2014; Li et al., 2015a). Deng et al. (2010) reported that the piezoelectric coefficient $\mathrm{d}_{33}$, dielectric constant $\varepsilon_{\mathrm{r}}$ and electromechanical coupling factor $\mathrm{k}_{\mathrm{p}}$ of the La doped $0.3 \mathrm{~Pb}\left(\mathrm{Zn}_{1 / 3} \mathrm{Nb}_{2 / 3}\right) \mathrm{O}_{3}-0.7 \mathrm{~Pb}\left(\mathrm{Zr}_{0.51} \mathrm{Ti}_{0.49}\right) \mathrm{O}_{3}$ can reach $845 \mathrm{pC} / \mathrm{N}$, 4,088 , and 0.70 , respectively. Wang et al. (2012) reported that $\mathrm{La}$ doped $0.25 \mathrm{~Pb}\left(\mathrm{Zn}_{1 / 3} \mathrm{Nb}_{2 / 3}\right) \mathrm{O}_{3}-0.75 \mathrm{~Pb}\left(\mathrm{Zr}_{0.53} \mathrm{Ti}_{0.47}\right) \mathrm{O}_{3}$ ceramics near the morphotropic phase boundary had good piezoelectric properties $\left(\mathrm{d}_{33}=570 \mathrm{pC} / \mathrm{N}, \mathrm{k}_{\mathrm{p}}=0.60\right)$. Fan et al. (2014) found that introducing the proper amount of $\mathrm{Li}_{2} \mathrm{CO}_{3}$ and $\mathrm{Sm}_{2} \mathrm{O}_{3}$ into $0.3 \mathrm{PZN}-0.7 \mathrm{PZT}$ ceramics could not only effectively improve the sinter ability and reduce the sintering temperature $\left(\sim 900^{\circ} \mathrm{C}\right)$, but also enhance the electric properties $\left(\mathrm{d}_{33}=483 \mathrm{pC} / \mathrm{N}, \varepsilon_{\mathrm{r}}=2,524\right.$, $\tan \delta=0.0178$ ).

\section{Rare-Earth Doped PMN-PT Ceramics}

$\mathrm{Pb}\left(\mathrm{Mg}_{1 / 3} \mathrm{Nb}_{2 / 3}\right) \mathrm{O}_{3}-\mathrm{PbTiO}_{3}(\mathrm{PMN}-\mathrm{PT})$ ceramic is another kind of typical lead-based ceramic, which has been widely applied in multilayer capacitors, actuators, electro-optical modulators, 
ultrasonic transducers, and infrared detectors due to the good electric properties $\left(\mathrm{d}_{33}=663 \mathrm{pC} / \mathrm{N}, \varepsilon_{\mathrm{r}}=5,260\right)$ (Choi et al., 1989; Kamzina et al., 2010; Zhang et al., 2014a).

Li et al. (2018) found an ultrahigh piezoelectricity in the Sm doped 0.71 PMN-0.29 PT ceramics. The piezoelectric constant $\mathrm{d}_{33}$ can reach as high as $1,500 \mathrm{pC} / \mathrm{N}$, and the dielectric constant $\varepsilon_{\mathrm{r}}$ can arrive at about 13,000 . But the Curie temperature decreased to $89^{\circ} \mathrm{C}$. Guo et al. (2019a) reported the enhancement of electric properties in the $0.72 \mathrm{PMN}-0.28 \mathrm{PT}$ ceramics doped with $2.5 \mathrm{~mol}$ $\% \mathrm{Eu}$. The piezoelectric constant $\mathrm{d}_{33}$, dielectric constant $\varepsilon_{\mathrm{r}}$, and electromechanical coupling coefficient $\mathrm{k}_{33}$ of the ceramics can reach $1,420 \mathrm{pC} / \mathrm{N}, 12,200$, and 0.78 , respectively. Guo et al. (2019b) also developed $\mathrm{Sm}$ doped $0.4 \mathrm{~Pb}\left(\mathrm{Mg}_{1 / 3} \mathrm{Nb}_{2 / 3}\right) \mathrm{O}_{3^{-}}$ $0.248 \mathrm{PbZrO}_{3}-0.352 \mathrm{PbTiO}_{3}$ ternary system ceramics. These ceramics possess a high piezoelectric constant $\left(d_{33}=910 \mathrm{pC} /\right.$ $\mathrm{N})$, good dielectric constant $\left(\varepsilon_{\mathrm{r}}=4,090\right)$, and relatively high Curie temperature $\left(\mathrm{T}_{\mathrm{c}}=184^{\circ} \mathrm{C}\right)$. The previous studies also proved that the optical properties of PMN-PT ceramics can be also significantly improved by rare-earth doping. Wei et al. (2010) achieved a much larger Kerr effect in the La doped 0.75 PMN0.25 PT transparent ceramic, The Kerr effect (second-order electro-optic effect) refers to the phenomenon of inductive birefringence that is proportional to the square of the electric field, providing useful devices such as light valves, deflectors and displays (Uchino, 1995). The quadratic electro-optic coefficient of the ceramics can reach as high as $66 \times 10^{-6} \mathrm{~m}^{2} / \mathrm{V}^{2}$. Wei et al. (2012a) and Wei et al. (2012b) reported that the transparency of the Er doped 0.75 PMN-0.25 PT ceramics can reach 65\% from visible light to infrared band. Besides, three broad peaks at $950-1,060,1,220-1,290$, and $1420-1560 \mathrm{~nm}$ can be observed under the excitation of a $521 \mathrm{~nm}$ laser. Liu et al. (2016) acquired a strong yellow-green up-conversion photoluminescence in the $\mathrm{Ho} / \mathrm{Yb}$ co-doped 0.67 PMN-0.33 PT ceramics under the excited of a $980 \mathrm{~nm}$ laser. Ma et al. (2018) reported La doped $0.88 \mathrm{PMN}-0.12 \mathrm{PT}$ transparent ceramics. The transparency in the near infrared region increased to $70 \%$ with $1.0 \mathrm{~mol} \%$ La doping. Fang et al. (2021) reported that the transparency and quadratic electro-optic coefficient of the Sm doped 0.88 PMN-0.21 PT transparent ceramics can reach $69.6 \%$ and $35 \times 10^{-6} \mathrm{~m}^{2} / \mathrm{V}^{2}$, respectively. Lv et al. (2019) obtained strong visible up-conversion emissions at 491, 529, 539, 623, 649, 685, 710 , and $737 \mathrm{~nm}$ and near-infrared down-conversion emissions around 1,061 nm and $1006 \mathrm{~nm}$ in the $\mathrm{Pr} / \mathrm{Yb}$ co-doped 0.75 PMN0.25 PT ceramics under the excitation of a $980 \mathrm{~nm}$ laser. These studies indicate that the rare-earth doped PMN-PT ceramics are promising multifunctional materials due to the improved electric properties, electro-optic effects, and various photoluminescence properties.

\section{Rare-Earth Doped BS-PT Ceramics}

The PMN-PT ceramics have good electric properties. However, the low Curie temperature $\left(159^{\circ} \mathrm{C}\right)$ limits their applications. By contrast, the $\mathrm{BiScO}_{3}-\mathrm{PbTiO}_{3}$ (BS-PT) ceramics exhibit a high Curie temperature $\left(\mathrm{T}_{\mathrm{c}} \sim 450^{\circ} \mathrm{C}\right)$ and good piezoelectric property $\left(\mathrm{d}_{33} \sim\right.$ $460 \mathrm{pC} / \mathrm{N}$ ) near the morphotropic phase boundary (Inaguma et al., 2004; Zhang et al., 2005). Yao et al. (2010) found the enhancement of the electric properties $\left(\mathrm{d}_{33}=361 \mathrm{pC} / \mathrm{N}, \mathrm{k}_{\mathrm{p}}=0.40\right)$ in the La doped
BS-PT ceramics. The highest Curie temperature can reach $467^{\circ} \mathrm{C}$. Politova et al. (2011) reported a large piezoelectric coefficient $\left(\mathrm{d}_{33}=\right.$ $350 \mathrm{pC} / \mathrm{N})$ and the piezoelectric coupling coefficient $\left(\mathrm{k}_{\mathrm{t}}=0.68\right)$ in the Nd doped BS-PT ceramics. Li et al. (2009) reported a high Curie temperature $\left(\mathrm{T}_{\mathrm{c}}=490^{\circ} \mathrm{C}\right)$ and good piezoelectric properties $\left(\mathrm{d}_{33}=\right.$ $\left.147 \mathrm{pC} / \mathrm{N}, \mathrm{k}_{\mathrm{p}}=0.28\right)$ in the $\mathrm{Y}$ doped BS-PT ceramics. The combination of high Curie temperature and good piezoelectric properties suggested that these rare-earth modified ceramics can be a promising candidate for high-temperature actuators and transducers. Table 1 shows the properties of some lead-based piezoelectric ceramics with rare-earth doping.

\section{Rare-Earth Doped Lead-free Ceramics}

Due to the increasing concern of lead pollution to the environment, it is significant and urgent to develop lead-free piezoelectric ceramics with good properties. There are three typical lead-free piezoelectric ceramics that have gained a lot of attention, including $\left(\mathrm{Na}_{0.5} \mathrm{Bi}_{0.5}\right) \mathrm{TiO}_{3}-\mathrm{BaTiO}_{3} \quad$ (NBT-BT) ceramic $\left(\mathrm{K}_{0.5} \mathrm{Na}_{0.5}\right) \mathrm{NbO}_{3}(\mathrm{KNN})$ based ceramic, and $\mathrm{BaTiO}_{3}$ (BT) ceramic, which are considered as possible substitutes for lead-based ceramics. The following section summaries the leadfree piezoelectric ceramics with rare-earth doping.

\section{Rare-Earth Doped BNT-BT Ceramic}

BNT-BT ceramic is one of the most widely used lead-free piezoelectric ceramics owing to the good piezoelectric constant and high Curie temperature $\left(\mathrm{d}_{33}>100 \mathrm{pC} / \mathrm{N}, \mathrm{T}_{\mathrm{c}}>280^{\circ} \mathrm{C}\right.$ ) (Panda, 2009; Jo et al., 2011). Li et al. (2004) reported the enhancement electric properties of the BNT-6BT ceramics doped with one at\% $\mathrm{La}$, showing the piezoelectric constant $\mathrm{d}_{33}$ increased from 117 to $125 \mathrm{pC} / \mathrm{N}$, but the thick electromechanical coupling coefficient $\mathrm{k}_{\mathrm{t}}$ decreased slightly from 0.43 to 0.38 . Liu et al. (2008) reported that the BNT-6BT ceramics doped with $0.4 \mathrm{wt} \% \mathrm{CeO}_{2}$ had better performances compared to pure BNT-6BT ceramics. The piezoelectric constant $\mathrm{d}_{33}$ and thick electromechanical coupling coefficient $\mathrm{k}_{\mathrm{t}}$ of the doped ceramics were $120 \mathrm{pC} / \mathrm{N}$ and 0.52 , respectively. Peng et al. (2010a), Peng et al. (2010b) and Peng et al. (2010c) reported the enhancement of electric properties in the Sm doped BNT-6BT ceramics. The piezoelectric constant $\mathrm{d}_{33}$ and coupling coefficient $\mathrm{k}_{\mathrm{p}}$ of the ceramics increased to $202 \mathrm{pC} / \mathrm{N}$ and 0.3 , respectively. In the same year, this group found that $\mathrm{Nd}$ doping can also improve the electric properties of BNT-6BT ceramics. The piezoelectric constant $\mathrm{d}_{33}$ and planar electromechanical coupling coefficient $\mathrm{k}_{\mathrm{p}}$ of the ceramics can reach $175 \mathrm{pC} / \mathrm{N}$ and 0.31 , respectively. Besides, this group also fabricated $\mathrm{La}_{2} \mathrm{O}_{3}$ doped BNT-6BT ceramics. After $0.6 \mathrm{wt} \% \mathrm{La}_{2} \mathrm{O}_{3}$ doping, the ceramics with showed good piezoelectric properties $\left(\mathrm{d}_{33}=167 \mathrm{pC} / \mathrm{N}, \mathrm{k}_{\mathrm{p}}=0.30\right)$.

Rare-earth doped BNT-BT ceramics also possess great photoluminescence properties. Jiang et al. (2018) reported the piezoelectric constant $\mathrm{d}_{33}$ and planar electromechanical coupling coefficient $\mathrm{k}_{\mathrm{p}}$ of the $2.5 \mathrm{~mol} \%$ Dy doped BNT-6BT ceramic can reach $190 \mathrm{pC} / \mathrm{N}$ and 0.372 , respectively. Moreover, the ceramics excited at $426 \mathrm{~nm}$ also exhibited strong emissions at 478 and $575 \mathrm{~nm}$. This study showed the Dy doped BNT-BT ceramics had simultaneously good piezoelectricity and photoluminescence, suggesting a promising application in the electro-optic devices. 
TABLE 1 | The properties of some lead-based piezoelectric ceramics with rare-earth doping

\begin{tabular}{|c|c|c|c|c|c|}
\hline Composition & $d_{33}(p C / N)$ & $\mathbf{k}_{\mathbf{p}}$ & $\varepsilon_{\mathrm{r}}$ & $\mathrm{T}_{\mathrm{c}}\left({ }^{\circ} \mathrm{C}\right)$ & Ref \\
\hline (Eu,La,Nd,Sm, Gd,Dy,Er):PZT & $53-569$ & - & $187-3,413$ & $156-368$ & Shannigrahi et al. (2004) \\
\hline $\mathrm{Sm}: \mathrm{PZT}$ & 172 & 0.42 & 610 & 274 & Pandey et al. (2009) \\
\hline (Pr,Yb,Sm):PZT & - & - & $210.48-7,000$ & $314-394$ & Samad et al. (2017) \\
\hline Sm:PMN-PT & 1,510 & - & 13,000 & 89 & Li et al. (2018) \\
\hline Eu: PMN-PT & 1,420 & 0.78 & 12,200 & 83 & Guo et al. (2019a) \\
\hline Sm-PMN-PZT & 910 & 0.7 & 4,090 & 184 & Guo et al. (2019b) \\
\hline La: PZN-PZT & $440-845$ & $0.63-0.7$ & $3,321-4,088$ & $206-213$ & Deng et al. (2010) \\
\hline La: PZN-PZT & 570 & 0.6 & 3,900 & 204 & Wang et al. (2012) \\
\hline Sm: PNN-PZT & 605 & 0.55 & 5,020 & 128 & Peng et al. (2016) \\
\hline Sm/Li:PZN-PZT & 483 & 0.65 & 2,524 & 394 & Fan et al. (2014) \\
\hline La:BS-PT & 361 & 0.4 & 3,500 & 467 & Yao et al. (2010) \\
\hline Y:BS-PT & 147 & 0.28 & - & 490 & Li et al. (2009) \\
\hline
\end{tabular}

Chi et al. (2015) observed visible up-conversion luminescence at 532,540 , and $600 \mathrm{~nm}$, as well as near infrared (1440-1660 nm) and mid-infrared (2620-2840 $\mathrm{nm}$ ) broadband down-conversion luminescence in the Er doped BNT-7BT ceramics under the excitation of $980 \mathrm{~nm}$. Li et al. (2019a) achieved a strong orange luminescence in the Sm doped BNT-12BT ceramics when excited by blue light, and the emission intensity depends largely on the doping concentration.

\section{Rare-Earth Doped KNN-Based Ceramics}

$\mathrm{KNN}$ ceramics with high Curie temperature $\left(\mathrm{T}_{\mathrm{c}} \sim 400^{\circ} \mathrm{C}\right)$ and good electric properties $\left(\mathrm{d}_{33} \sim 80 \mathrm{pC} / \mathrm{N}, \mathrm{k}_{\mathrm{p}} \sim 0.36\right)$ have been deemed as potential candidates for lead-based piezoelectric ceramics (Saito et al., 2004; Birol et al., 2006; Jaeger. 2010).

Du et al. (2017) studied the effect of the KNN ceramics doped with different rare-earth elements (Dy, Er, Eu, and Pr). The piezoelectric constant $\mathrm{d}_{33}$ increased slightly after doping, (KNNDy: 95 pC/N, KNN-Er: 91 pC/N, KNN-Eu: 84 pC/N and KNNPr: 94 pC/N). Wu et al. (C2017) fabricated Er doped KNN based ceramics with the piezoelectric constant of 70-90 pC/N, and the dielectric constant and loss is about 1,400 and 0.03, respectively. Zhai et al. (2019) reported good piezoelectric and ferroelectric properties in the KNN ceramics doped with $\mathrm{Tb}$ and $\mathrm{Tm}$. The $\mathrm{d}_{33(\mathrm{~Tb})}$ and $\mathrm{d}_{33(\mathrm{Tm})}$ can reach $140 \mathrm{pm} / \mathrm{V}$ and $127 \mathrm{pm} / \mathrm{V}$, respectively.

In addition to studying the electric properties, the optical performances of rare-earth doped $\mathrm{KNN}$ ceramics were also investigated extensively. Yang et al. (2017) reported that the transparency of $1.5 \mathrm{~mol} \% \mathrm{La}_{2} \mathrm{O}_{3}$ doped $\mathrm{KNN}$ ceramic can reach as high as 74\%). Geng et al. (2017) reported that $\mathrm{Eu}$ doped $\mathrm{K}_{0.47} \mathrm{Na}_{0.47} \mathrm{Li}_{0.06} \mathrm{Nb}_{0.94} \mathrm{Bi}_{0.06} \mathrm{O}_{3} \quad$ ceramics presented high transmittance both in the near-infrared and middle infrared regions (close to 100\%). Besides, the ceramics were efficiently excited by near-ultraviolet and blue light to realize strong reddish luminescence. Sun et al. (2012), and Sun et al. (2014) observed strong green $(528 \mathrm{~nm})$ and red $(617$ and $650 \mathrm{~nm})$ emissions in the Pr doped KNN ceramics under the excitation of $450 \mathrm{~nm}$. Two years later, this group found strong green $(510-590 \mathrm{~nm})$ and a relatively weak red (645-695 nm) emissions in the Er doped KNN ceramics under the $980 \mathrm{~nm}$ excitation, and it is possible to modulate the ratio of red to green emission by adjusting the Er concentration. Similarly, Wu et al. (2013), Wu et al. (2015a), and Wu et al. (2015b) found that the Er doped KNN ceramics fabricated by sol-gel method exhibited luminescent bands at 527, 548, 660, and $487 \mathrm{~nm}$ under the excitation of $980 \mathrm{~nm}$. Besides, Er doping is beneficial to the formation of fine and uniform grains, which helps to enhance the up-conversion efficiency and luminous efficiency. Furthermore, seven down conversion emission bands (530, 548, $605,618,650,672$, and $740 \mathrm{~nm}$ ) could be observed in the Er and Pr co-doped KNN ceramics under the excitation of $485 \mathrm{~nm}$. Besides, three up-conversion emission bands $(510-537 \mathrm{~nm}, 537-585 \mathrm{~nm}$, and 640-690 nm), and two down-conversion emission bands $(1,400-1700 \mathrm{~nm}$ and 2,600-2,850 nm) were found in the Er and $\mathrm{Yb}$ co-doped KNN ceramics. Zhang et al. (2014b) also achieved a strong orange emission in the Sm doped KNN ceramics under the excitation from 400 to $500 \mathrm{~nm}$. Li et al. (2020a) also observed a bright photoluminescence with a strong orange emission in the $\mathrm{Sm}$-doped $0.96\left(\mathrm{~K}_{0.48} \mathrm{Na}_{0.52}\right) \quad\left(\mathrm{Nb}_{0.95} \mathrm{Sb}_{0.05}\right)-0.04 \mathrm{Bi}_{0.5}\left(\mathrm{Na}_{0.82} \mathrm{~K}_{0.18}\right)_{0.5} \mathrm{ZrO}_{3}$ ceramics under visible light irradiation.

\section{Rare-Earth Doped BT Ceramic}

$\mathrm{BT}$ ceramic has received much attention due to the high dielectric constant, high resistivity and outstanding insulation performance, which has been extensively applied in positive temperature coefficient of resistivity (PTCR) thermistors, multilayer ceramic capacitors (MLCC), piezoelectric devices, optoelectronic elements, and semiconductors (Zhou et al., 2001). Among them, the application of MLCC is extremely wide, for improving the dielectric constant to meet the requirements of high capacitance. It is effective in significantly increasing the dielectric constant of BT ceramics with rare-earth doping (Caballero et al., 2000; Morrison et al., 2001).

Sun et al. (2010) reported the enhancement of dielectric properties in the Sm doped BT ceramics. Sm doping can inhibit the growth of the crystal grains and make the BT ceramics possess semiconductor characteristics. Li et al. (2012) achieved a large dielectric constant $(70,000 \sim 80,000)$ and low dielectric loss $(<0.04)$ in the Tb doped BT ceramics. Zhang et al. (2020a) reported the $\mathrm{Yb} / \mathrm{Mn}$ co-doped BT ceramic possessed a relatively good performance with dielectric constant $\varepsilon_{\mathrm{r}}(>2,600)$, low dielectric loss $\tan \delta(0.0183)$ and high insulation resistivity $\left(4.38 \times 10^{11} \Omega \mathrm{cm}\right)$. Zhang et al. (2020b) reported the dielectric constant can reach $5,091.7$ for $0.3 \mathrm{~mol} \% \mathrm{La}_{2} \mathrm{O}_{3}$ doped BT ceramic. Kumari et al. (2020) reported that the relative dielectric constant 
TABLE 2 | The properties of some lead-free based piezoelectric ceramics with rare-earth doping.

\begin{tabular}{|c|c|c|c|c|c|}
\hline Composition & $d_{33}(p C / N)$ & $\mathbf{k}_{\mathbf{p}}$ & $\varepsilon_{\mathrm{r}}$ & $\mathrm{T}_{\mathrm{c}}\left({ }^{\circ} \mathrm{C}\right)$ & Ref \\
\hline La:BNT-6BT & 125 & 0.24 & - & 250 & Li et al. (2004) \\
\hline Ce: BNT-6BT & 127 & 0.23 & 851 & 280 & Liu et al. (2008) \\
\hline Sm:BNT-6BT & 202 & 0.3 & 1,200 & 277 & Peng et al. (2010a) \\
\hline Nd:BNT-6BT & 175 & 0.31 & 1,400 & 280 & Peng et al. (2010b) \\
\hline La:BNT-6BT & 167 & 0.3 & 1,470 & 272 & Peng et al. (2010c) \\
\hline Dy:BNT-6BT & 190 & 0.372 & 1,100 & 275 & Jiang et al. (2018) \\
\hline$(\mathrm{La}, \mathrm{Ho}, \mathrm{Yb}, \mathrm{Y}): \mathrm{BT}-\mathrm{Mn}$ & - & - & $2,108-2,613$ & - & Zhang et al. (2020a) \\
\hline (Dy,Er.Eu,Pr):KNN & 84-95 & - & - & - & Du et al. (2017) \\
\hline Sm:KNN-LS & 176 & 0.35 & 1,372 & 328 & Hao et al. (2015) \\
\hline (Nd, Dy, Ho):KNN-Li & $68-128$ & - & $247-807$ & $400-433$ & Zhou et al. (2014) \\
\hline Er: KNN-Li,Bi & 89 & - & 1,350 & 350 & Wu et al. (2017) \\
\hline
\end{tabular}

$\varepsilon_{\mathrm{r}}$ of the BT ceramics doped with Eu can increase to 8,581, and the grains of the ceramics was uniform with average grain size of $800 \mathrm{~nm}$. These studies indicated that BT ceramics doped with rare-earth may be a promising candidate for MLCC applications. Besides, Battisha et al. (2010) reported the up-conversion of infrared light to visible light can be observed in $\mathrm{Er} / \mathrm{Yb} \mathrm{co}-$ doped BT ceramics. Cernea et al. (2013) observed three distinct peaks $(483,660$, and $800 \mathrm{~nm})$ in the BT ceramics doped with Tm under the excitation of $460 \mathrm{~nm}$.

Thus, rare-earth doped piezoelectric ceramics can effectively modify the electric properties and introduce excellent photoluminescence properties, which expanded the applications of piezoelectric ceramics greatly, such as actuating device, ultrasonic transducers, electro-optical deflector, potential phosphor, and multifunctional optoelectronics. Table 2 summarizes the properties of some lead-free based piezoelectric ceramics with rare-earth doping.

\section{RARE-EARTH DOPED PIEZOELECTRIC SINGLE CRYSTALS}

\section{Rare-Earth Doped Lead-Based Single Crystals}

In order to further improve the properties of the piezoelectric materials, the growth of piezoelectric single crystals has drawn wide concern. The discovery of relaxor-based ferroelectric single crystals represented by $\mathrm{Pb}\left(\mathrm{Mg}_{1 / 3} \mathrm{Nb}_{2 / 3}\right) \mathrm{O}_{3}-\mathrm{PbTiO}_{3}(\mathrm{PMN}-\mathrm{PT})$ and $\mathrm{Pb}\left(\mathrm{Zn}_{1 /}\right.$ $\left.{ }_{3} \mathrm{Nb}_{2 / 3}\right) \mathrm{O}_{3}-\mathrm{PbTiO}_{3}(\mathrm{PZN}-\mathrm{PT})$ are considered as a revolutionary breakthrough of piezoelectric materials, which tremendously improved the electric properties $\left(\mathrm{d}_{33}=1780 \mathrm{pC} / \mathrm{N}\right)$ of piezoelectric materials compared to commercial piezoelectric PZT-5H ceramics (590 pC/N) (Kim et al., 2010).

Li et al. (2019b) reported a large piezoelectric constant $d_{33}$ in the Sm doped PMN-PT single crystals, and the values (exceeding $3,400 \mathrm{pC} / \mathrm{N}$ ) increased more than double compared with the Sm doped PMN-PT ceramics $(1,510 \mathrm{pC} / \mathrm{N})$. The $\mathrm{Sm}$ doped single crystals also showed improved compositional uniformity along the crystal boule. Furthermore, the electric field-induced strain can reach $30 \%$, which is almost $90 \%$ higher than that of undoped PMN-PT single crystals. This study provided commercial opportunities for high-performance piezoelectric applications. Besides, PZN-9PT piezoelectric single crystal showed excellent electric properties $\left(d_{33}>1500 \mathrm{pC} / \mathrm{N}, \mathrm{k}_{33}>90 \%\right)$ near the morphotropic phase boundary (Kuwata et al., 1982). However, the low coercive field $(\mathrm{Ec} \sim 3.5 \mathrm{kV} / \mathrm{cm})$ and low Curie temperature $\left(\mathrm{T}_{\mathrm{c}} \sim\right.$ $170^{\circ} \mathrm{C}$ ) limit the application of PZN-PT single crystal in high-power and high-temperature environments (Rajan et al., 2007). Xi et al. (2016a) and Xi et al. (2016b) reported a significantly enhanced coercive field $\mathrm{E}_{\mathrm{c}}(11.6 \mathrm{kV} / \mathrm{cm})$ in the Er doped PZN-9PT crystal. The Curie temperature $\mathrm{T}_{\mathrm{c}}$ was around $178^{\circ} \mathrm{C}$. Furthermore, the green and red up-conversion emission bands can be obtained in the ceramic under the $980 \mathrm{~nm}$ excitation. The group also reported the enhancement of the coercive field $\left(\mathrm{E}_{\mathrm{c}}=5.9 \mathrm{kV} / \mathrm{cm}\right)$, remnant polarization $\left(\mathrm{P}_{\mathrm{r}}=38.40 \mu \mathrm{C} / \mathrm{cm}^{2}\right)$ and Curie temperature $\left(\mathrm{T}_{\mathrm{c}}=\right.$ $175^{\circ} \mathrm{C}$ ) in the Ho doped PZN-9PT crystal. Li et al. (2019c) also prepared $\mathrm{Tm} / \mathrm{Yb}$ co-doped PZN-9PT crystal with large coercive field $\mathrm{E}_{\mathrm{c}}$ of $12.1 \mathrm{kV} / \mathrm{cm}$, and the value is nearly four times higher than that of PZN-9PT crystal. The Curie temperature $\mathrm{T}_{c}$ was increased to $182.5^{\circ} \mathrm{C}$. Under a $980 \mathrm{~nm}$ laser excitation, the modified crystals produce up-conversion with three colors [blue $(480 \mathrm{~nm})$, strong near-infrared (804 nm), and weak red (652 nm)]. Chen et al. (2020b) and Chen et al. (2020c) reported the coercive field $E_{c}$ of Eu doped PZN-9PT crystal significantly increased to $11.0597 \mathrm{kV} / \mathrm{cm}$, and it is triple higher than that of pure PZN-9PT crystal. Besides, under the excitation of $464 \mathrm{~nm}$, four broadband peaks appear at around $593 \mathrm{~nm}, 613 \mathrm{~nm}, 657 \mathrm{~nm}$, and $716 \mathrm{~nm}$, respectively. Furthermore, the group also achieved a high Curie temperature $\left(\mathrm{T}_{\mathrm{c}}=250^{\circ} \mathrm{C}\right)$ and large coercive field $\left(\mathrm{E}_{\mathrm{c}}=11.0597 \mathrm{kV} / \mathrm{cm}\right)$ in the $0.15 \mathrm{~Pb}\left(\mathrm{Er}_{1 / 2} \mathrm{Nb}_{1 / 2}\right)$ $\mathrm{O}_{3}-0.63 \mathrm{~Pb}\left(\mathrm{Zn}_{1 / 3} \mathrm{Nb}_{2 / 3}\right) \mathrm{O}_{3}-0.22 \mathrm{PbTiO}_{3}$ single crystal, and the crystal also exhibited a strong green light excited by a $980 \mathrm{~nm}$ laser. As mentioned above, the addition of rare-earth not only improves the temperature and electric field stability of PZN-PT single crystals but also induces photoluminescence properties, which gives the rareearth doped PZN-PT single crystals possibilities for multifunctional optoelectronic device applications.

\section{Rare-Earth Doped Lead-free Single Crystals}

$\mathrm{Na}_{0.5} \mathrm{Bi}_{0.5} \mathrm{TiO}_{3}$ (BNT)-based lead-free crystals were reported to have superior electric properties, large band gap and high near-visible light absorption coefficient (Hiruma et al., 2010; Li et al., 2015b). In recent years, the electric and optical properties of 
the rare-earth doped BNT single crystals have been studied. Zhang et al. (2014c) prepared an Eu doped BNT single crystal by top-seeded solution growth, and observed that the crystal presented orange and red emissions under the excitation of $611 \mathrm{~nm}$. The piezoelectric constant $\mathrm{d}_{33}$ and remnant polarization $\mathrm{P}_{\mathrm{r}}$ of the crystal increased to $86 \mathrm{pC} / \mathrm{N}$ and $7.38 \mu \mathrm{C} / \mathrm{cm}^{2}$, respectively. Jiang et al. (2018) achieved an extremely strong green emission in the Er doped BNT single crystal under the $980 \mathrm{~nm}$ near-infrared excitation. But Er doping led to a slight decreasing of dielectric constant, dielectric loss and transmittance. He et al. (2013) reported high transparency $\mathrm{Nd}$ doped NBT single crystal by a top seeded solution growth method. The transparency reached more than 50\% above $450 \mathrm{~nm}$, and a strong emission band around 1,066 nm was found under laser excitation at $808 \mathrm{~nm}$. These research results may help to extend various biomedical applications including intravascular imaging, photoacoustic imaging, and microbeam applications.

\section{RARE-EARTH DOPED PIEZOELECTRIC FILMS}

Compared to piezoelectric crystal and ceramics, piezoelectric films can greatly improve the operating frequency due to unlimited size. Currently, piezoelectric films such as PZT and $\mathrm{Bi}_{4} \mathrm{Ti}_{3} \mathrm{O}_{12}$ (BIT) thin films are widely applied in ferroelectric dynamic random-access memory, room temperature infrared detectors, piezoelectric motors, ultrasonic detectors, film capacitors and integrated optical waveguide devices (Xie et al., 2006).

\section{Rare-Earth Doped PZT Films}

Majumder et al. (2001) investigated rare-earth (Nd, Gd, and Ce) doped PZT (53/47) thin films by sol-gel technique, realizing an improvement of ferroelectric and dielectric properties of the PZT thin films with Ce and Gd. Nd doping was effective to increase the retained switchable polarization of PZT from 63 to $84 \%$. Yu et al. (2003) fabricated the Eu doped PZT (52/42) thin films with an improved polarization and low leakage current by a sol-gel method. Nakaki et al. (2004) studied the effect of the PZT $(40 / 60)$ thin films doped with various rare-earth elements (Y, $\mathrm{Dy}, \mathrm{Er}$, and $\mathrm{Yb})$. The remnant polarization $\mathrm{P}_{\mathrm{r}}$ of the films increased to 26 (PZT-Y), 25 (PZT-Dy) and $26 \mu \mathrm{C} / \mathrm{cm}^{2}$ (PZT$\mathrm{Er})$, respectively, while $\mathrm{Yb}$ doping degraded the remnant polarization $\mathrm{P}_{\mathrm{r}}$ down to $16 \mu \mathrm{C} / \mathrm{cm}^{2}$. Pandey et al. (2007) reported the remnant polarization and dielectric constant of the Sm substituted PZT (65/35) thin films can reach about $52 \mu \mathrm{C} / \mathrm{cm}^{2}$ and 1,220 , respectively. Moreover, the transparency of the film was close to $80 \%$ at $1200 \mathrm{~nm}$. Rath et al. (2019) reported the enhancement of piezoelectric constant $d_{33}$ (more than $130 \mathrm{pm} / \mathrm{V}$ ) in La doped PZT film. Zhang et al. (2021) achieved a large remnant polarization $\left(22.73 \mu \mathrm{C} / \mathrm{cm}^{2}\right)$ in the 2 mol\% Dy doped PZT (60/40) thin films. Moreover, the films also exhibited a significantly reduced leakage current density. All these studies indicated that rare-earth doping is one promising technique for improving the ferroelectric property of PZT film to meet a wide range of application requirements.

\section{Rare-Earth Doped Lead-free Films}

Due to the fatigue-free characteristics, the BIT films have been widely used in special applications, typically like nonvolatile ferroelectric random access memory. Kim et al. (2002) reported the enhancement of ferroelectric properties in the Eu doped BIT films. The remnant polarization $\mathrm{P}_{\mathrm{r}}$ of the films was about $30 \mu \mathrm{C} / \mathrm{cm}^{2}$. Zhang et al. (2003) reported that the remnant polarization of $\mathrm{Nd}$ doped BIT films increased double $(8.8 \mu \mathrm{C} /$ $\mathrm{cm}^{2}$ ) compared to the pure BIT films. Ruan et al. (2008) reported a high optical transparency $(>80 \%)$ in the Eu doped BIT films, and the emission spectra of the films presented two peaks at 594 and $617 \mathrm{~nm}$ under the excitation of $350 \mathrm{~nm}$. Moreover, the films exhibited high fatigue resistance after $10^{10}$ switching cycles. Gao et al. (2009) observed two strong green emission bands centered at 524 and $545 \mathrm{~nm}$ and a weak red emission band centered at $667 \mathrm{~nm}$ in the Er/Yb co-doped BIT films under the excitation of $980 \mathrm{~nm}$. Ding et al. (2011) observed two emission bands centered at 546 and $656 \mathrm{~nm}$ in the $\mathrm{Ho} / \mathrm{Yb}$ co-doped BIT thin films under the excitation of $980 \mathrm{~nm}$.

In addition to the research of rare-earth doped piezoelectric thin films, Xu et al. (2020) have also made remarkable achievements in the thick films. They obtained high $\mathrm{d}_{33}$ $(343 \mathrm{pC} / \mathrm{N})$, large $\mathrm{P}_{\mathrm{r}}\left(12.45 \mu \mathrm{C} / \mathrm{cm}^{2}\right)$ and low $\mathrm{E}_{\mathrm{c}}(0.63 \mathrm{kV} / \mathrm{mm})$ in the Er doped $\mathrm{Ba}_{0.85} \mathrm{Ca}_{0.15} \mathrm{Ti}_{0.9} \mathrm{Zr}_{0.1} \mathrm{O}_{3}$ textured thick films. Besides, two strong green emission bands centered at 525 and $550 \mathrm{~nm}$ and one weak red emission band of $660 \mathrm{~nm}$ were acquired under the excitation of a $980 \mathrm{~nm}$ laser. These results showed that rare-earth doped films significantly enhanced the electrical properties as well as the photoluminescence performances, which has high potential for multifunctional film devices applications.

\section{DISCUSSIONS}

\section{Electrical Properties}

The rare-earth doping may influence the electrical and optical performances of the piezoelectric materials significantly. Two tables (Tables 1, 2) and Figure 3 summary the piezoelectric properties of the rare-earth doped piezoelectric ceramics with perovskite $\left(\mathrm{ABO}_{3}\right)$ structure. It can be found that $\mathrm{Sm}$ doped PMN-PT ceramics exhibited the highest piezoelectric constants $(1,510 \mathrm{pC} / \mathrm{N})$ among the rare-earth doped ceramics listed, which may be due to the addition of aliovalent $\mathrm{Sm}^{3+}$ dopant on A-site of the perovskite structure with similar ion radius. It is noting that $\mathrm{Sm}^{3+}$ is the smallest ion among all the lanthanide rare Earth ions, which may completely occupy the A-site of PMN-PT solid solution and then replace the $\mathrm{Pb}$ ion ( $\mathrm{Li}$ et al., 2020b). The significant effect on electric properties of Sm doping PMN-PT is mainly due to the local structure disorder. Besides, $\mathrm{Eu}^{3+}$ doped PMN-PT ceramics also exhibit excellent piezoelectric properties $\left(\mathrm{d}_{33} \sim 1420 \mathrm{pC} / \mathrm{N}\right)$. As we know, the $\mathrm{Eu}^{3+}$ have similar ionic radius and valence states to $\mathrm{Sm}^{3+}$ ions, which also proved that the rare 


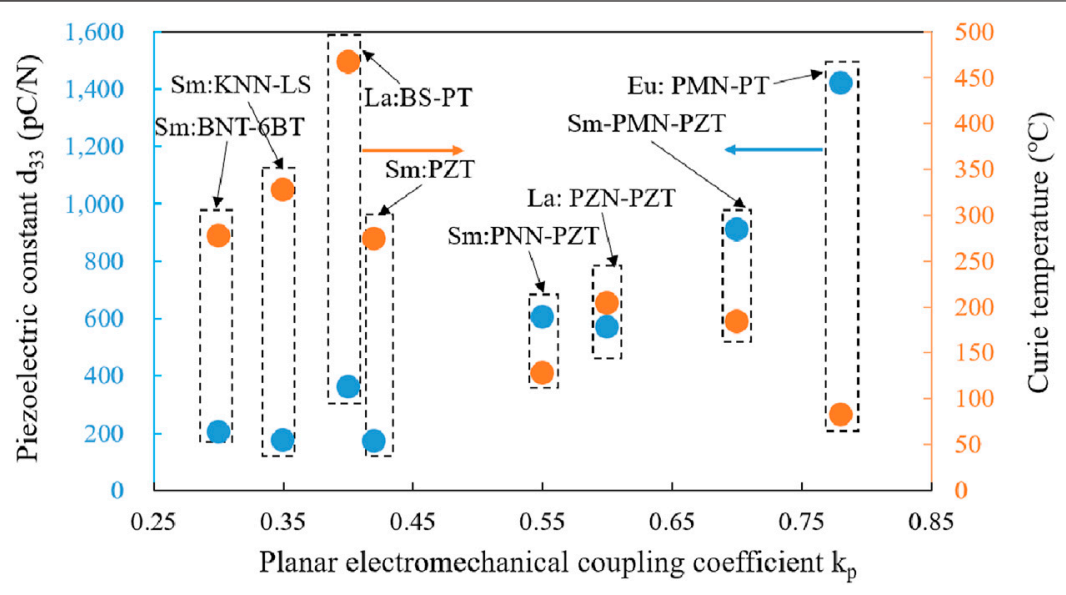

FIGURE 3| The properties of some piezoelectric ceramics with rare-earth doping (Pandey et al., 2009; Peng et al., 2010a; Yao et al., 2010; Wang et al., 2012; Hao et al., 2015; Peng et al., 2016; Guo et al., 2019a; Guo et al., 2019b).

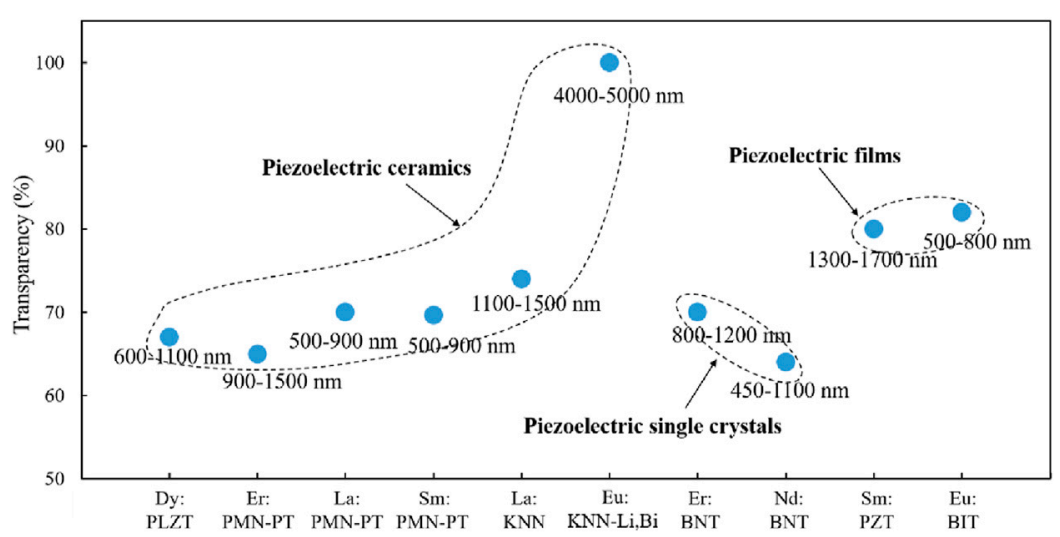

FIGURE 4 | The transmittance of some rare Earth doped piezoelectric materials in a certain wavelength range [with the thickness of $0.35 \mathrm{~mm}$ (Dy:PLZT); $0.6 \mathrm{~mm}$ (La:PMN-PT); 0.85 mm (Sm:PMN-PT); 0.5 mm (La:KNN); 0.5 mm (Eu: KNN-Li,Bi); 1 mm (Nd:BNT); 300 nm (Eu:BIT)] (Pandey et al., 2007; Ruan et al., 2008; Wei et al., 2012b; He et al., 2013; Zeng et al., 2014; Geng et al., 2017; Yang et al., 2017; Jiang et al., 2018; Ma et al., 2018; Fang et al., 2021).

Earth ions with a similar ionic radius to the A-site ions of the perovskite ferroelectric materials can be used to improve piezoelectric performance. Nevertheless, Sm doping reduced the Curie temperature of PMN-PT $\left(89^{\circ} \mathrm{C}\right)$ that would limit their high temperature applications. The RE doped lead-based (PMN-PZT and BS-PT) and lead-free based (BNT and KNN) materials with relatively high Curie temperature were studied for enhancing piezoelectric constant. Therefore, it is difficult to obtain the samples with both excellent piezoelectric constant and high Curie temperature and more research works will be needed in the future to improve performances by regulating the local structure disorder of piezoelectric materials with a stale Curie temperature.

\section{Optical Properties}

Except for the electric properties, the optical performances were discussed. On the one hand, the rare-earth doping can obtain transparent samples with high transmittance. Figure 4 gives the transmittance of some piezoelectric materials with rare-earth doping. It can be found that the transparency of the listed piezoelectric materials exceeds $60 \%$ in a specific wavelength range. For the ceramics, the grain boundary scattering loss is the main factor affecting the transmittance. Without exceeding the solubility limit, rare-earth can dissolve into the perovskite lattice homogeneously, meanwhile enhance the ceramic density, transparency, and other properties. However, excessive rare-earth ions may accumulate at the grain boundaries with increasing rareearth content, which will lead to Rayleigh scattering loss due to the different refractive indices between grain boundaries and matrix. Besides, ion vacancies and crystal defects as well as the defectinduced poor crystallinity may decrease the transparency. Therefore, optimizing these factors to further improve the transparency of rareearth doped piezoelectric materials may promote the development of multifunctional optical devices greatly.

One the other hand, the rare-earth doped piezoelectric materials can get characteristic emission spectrum after being 
excited due to the ladder-shaped $4 \mathrm{f}$ energy level of rare-earth ions (Figure 2). Under the excited of 300-500 nm, some sharp downconversion emissions can be achieved in the rare-earth doped materials. Typically, Eu ${ }^{3+}$ doping can acquire red $\left(617 \mathrm{~nm},{ }^{5} \mathrm{D}_{0} \rightarrow\right.$ ${ }^{7} \mathrm{~F}_{2}$ ) emission, and $\mathrm{Sm}^{3+}$ doping can get red $\left(645 \mathrm{~nm},{ }^{4} \mathrm{G}_{5 / 2} \rightarrow{ }^{6} \mathrm{H}_{9 /}\right.$ 2) and orange (563 nm, ${ }^{4} \mathrm{G}_{5 / 2} \rightarrow{ }^{6} \mathrm{H}_{5 / 2}$ ) emissions. $\operatorname{Pr}^{3+}$ doping can obtain green $\left(545 \mathrm{~nm},{ }^{3} \mathrm{P}_{0} \rightarrow{ }^{3} \mathrm{H}_{5}\right)$ and red $\left(617 \mathrm{~nm},{ }^{3} \mathrm{P}_{0} \rightarrow{ }^{3} \mathrm{H}_{6}\right)$ emissions. Besides, some sharp up-conversion emissions can be also achieved in the rare-earth doped materials under the excitation of $980 \mathrm{~nm}$. Green $\left(500 \mathrm{~nm},{ }^{2} \mathrm{G}_{11 / 2},{ }^{4} \mathrm{~S}_{3 / 2} \rightarrow{ }^{4} \mathrm{I}_{15 / 2}\right)$ and red $\left(670 \mathrm{~nm},{ }^{4} \mathrm{~F}_{9 / 2} \rightarrow{ }^{4} \mathrm{I}_{15 / 2}\right)$ emissions can be found for $\mathrm{Er}^{3+}$ doped samples, and blue $\left(480 \mathrm{~nm},{ }^{1} \mathrm{G}_{4} \rightarrow{ }^{3} \mathrm{H}_{6}\right)$ and red $\left(652 \mathrm{~nm},{ }^{1} \mathrm{G}_{4} \rightarrow{ }^{3} \mathrm{~F}_{4}\right.$ ) emissions can be observed in $\mathrm{Tm}^{3+} / \mathrm{Yb}^{3+}$ codoped samples. Green $\left(529 \mathrm{~nm}{ }^{3} \mathrm{P}_{0} \rightarrow{ }^{3} \mathrm{H}_{5}\right)$, orange $(623 \mathrm{~nm}$ $\left.{ }^{3} \mathrm{P}_{0} \rightarrow{ }^{3} \mathrm{H}_{6}\right)$ and red $\left(649 \mathrm{~nm}{ }^{3} \mathrm{P}_{0} \rightarrow{ }^{3} \mathrm{~F}_{2}\right)$ emissions were found in $\mathrm{Pr}^{3+} / \mathrm{Yb}^{3+}$ co-doped materials. The introduced photoluminescence performance can significantly expand the application range of piezoelectric materials. Especially, the materials can achieve up-conversion emissions with converting long-wavelength light (invisible to the naked eye) into visible light, which will have important application in the information science and technology fields such as laser, display, anti-counterfeiting, and will also open up new research fields in biomedicine or photoacoustic multi-mode images. However, some conditions including doping concentration, sintering temperature, chemical composition and preparation process have a great influence on the electrical performance and luminescence performance of the rare-earth doped piezoelectric materials. Adjusting these conditions to obtain both good electrical and optical properties is of great significance for the development of multifunctional materials and devices.

\section{CONCLUSION AND PERSPECTIVE}

The electric and photoluminescence properties of piezoelectric materials can be significantly modified by rare-earth doping.

\section{REFERENCES}

Battisha, I. K., Badr, Y., Shash, N. M., El-Shaarawy, M. G., and Darwish, A. G. A. (2010). Detection of Up-Conversion in Nano-Structure $\mathrm{BaTiO}_{3} \mathrm{Co}$-doped with $\mathrm{Er}^{3+}$ and $\mathrm{Yb}^{3+}$ Ions. J. Sol-gel Sci. Technol. 53, 543-550. doi:10.1007/s10971009-2129-5

Birol, H., Damjanovic, D., and Setter, N. (2006). Preparation and Characterization of (K0.5Na0.5)NbO3 Ceramics. J. Eur. Ceram. Soc. 26, 861-866. doi:10.1016/ j.jeurceramsoc.2004.11.022

Caballero, A. C., Fernández, J. F., Villegas, M., Moure, C., Durán, P., Florian, P., et al. (2000). Intermediate Phase Development in Phosphorus-Doped Barium Titanate. J. Am. Ceram. Soc. 83, 1499-1505. doi:10.1111/j.11512916.2000.tb01417.x

Cernea, M., Secu, C. E., Vasile, B. S., and Secu, M. (2013). Structural and Optical Characterization of Sol-Gel Derived Tm-Doped $\mathrm{BaTiO}_{3}$ Nanopowders and Ceramic. Curr. Appl. Phys. 13, 137-141. doi:10.1016/j.cap.2012.06.024

Chen, C., Wang, X., Wang, Y., Yang, D., Yao, F., Zhang, W., et al. (2020a). Additive Manufacturing of Piezoelectric Materials. Adv. Funct. Mater. 30, 2005141. doi:10.1002/adfm.202005141

Chen, Y., Bao, X., Wong, C.-M., Cheng, J., Wu, H., Song, H., et al. (2018). PZT Ceramics Fabricated Based on Stereolithography for an Ultrasound Transducer
Consequently, rare-earth doping is an effective method to fabricate multifunctional materials. The research and development trend of rare-earth doped piezoelectric materials are prospected as follows. 1) With the needs of environmental protection and sustainable development of human society, it is urgent to develop environmental friendly lead-free piezoelectric materials with excellent performance to replace traditional leadbased ceramics. The future development trend is to find an appropriate concentration of rare-earth oxide and proper leadfree piezoelectric materials to achieve excellent electric properties. 2) For the large strain and high energy conversion efficiency applications, rare-earth doped piezoelectric single crystals are superior to traditional piezoelectric ceramics due to their great electric properties. The future development trend is to optimize the growth conditions and properties of single crystals to meet increasingly demanding applications. 3) The rare-earth doped piezoelectric materials are a type of optical-mechanical-electric integrated multifunctional material. Due to the unique properties of rare-earth ions and piezoelectric materials, this type of new material has great advantages in sensing, detection, and information transmission.

\section{AUTHOR CONTRIBUTIONS}

YC and DZ wrote and edited the manuscript. ZP, MY, and XJ conceived the project and edited the manuscript.

\section{FUNDING}

This work was financially supported by National Science Foundation Grants (NSFC Grant No. 11804059, 51975131, 51805097), Guangdong Innovative and Entrepreneurial Research Team Program (Grant No. 2016ZT06G375) and Ministry of Science and Technology of China (Grant No. 2018YFF01010500).

Array Application. Ceramics Int. 44, 22725-22730. doi:10.1016/ j.ceramint.2018.09.055

Chen, Y., Xi, Z., Guo, F., Fang, P., Li, X., Long, W., et al. (2020b). Electric and Photoluminescence Properties of $\mathrm{Eu}^{3+}$-Doped PZN-9PT Single crystal. J. Mater. Sci. Mater. Electron. 31, 11295-11302. doi:10.1007/s10854-02003678-Z

Chen, Y., Xi, Z., Guo, F., Fang, P., Li, X., Long, W., et al. (2020c). $\mathrm{Pb}\left(\mathrm{Er}_{1 / 2} \mathrm{Nb}_{1 / 2}\right) \mathrm{O}_{3^{-}}$ $\mathrm{Pb}\left(\mathrm{Zn}_{1 / 3} \mathrm{Nb}_{2 / 3}\right) \mathrm{O}_{3}-\mathrm{PbTiO}_{3}$ Single Crystals with High Curie Temperature. Crystals 10, 22-43. doi:10.3390/cryst10010022

Choi, S. W., Shrout, R. T. R., Jang, S. J., and Bhalla, A. S. (1989). Dielectric and Pyroelectric Properties in the $\mathrm{Pb}\left(\mathrm{Mg}_{1 / 3} \mathrm{Nb}_{2 / 3}\right) \mathrm{O}_{3}-\mathrm{PbTiO}_{3}$ system. Ferroelectrics 100, 29-38. doi:10.1080/00150198908007897

Dang, S., Sun, L.-N., Zhang, H.-J., Guo, X.-M., Li, Z.-F., Feng, J., et al. (2008). NearInfrared Luminescence from Sol-Gel Materials Doped with Holmium(III) and Thulium(III) Complexes. J. Phys. Chem. C 112, 13240-13247. doi:10.1021/ jp8041632

de Camargo, A. S. S., Botero, É. R., Garcia, D., Eiras, J. A., and Nunes, L. A. O. (2005). $\mathrm{Nd}^{3+}$-doped lead Lanthanum Zirconate Titanate Transparent Ferroelectric Ceramic as a Laser Material: Energy Transfer and Stimulated Emission. Appl. Phys. Lett. 86, 152905. doi:10.1063/1.1899752

de Camargo, A. S. S., de O. Nunes, L. A., Santos, I. A., Garcia, D., and Eiras, J. A. (2004). Structural and Spectroscopic Properties of Rare-Earth $\left(\mathrm{Nd}^{3+}, \mathrm{Er}^{3+}\right.$, and 
$\mathrm{Yb}^{3+}$ ) Doped Transparent lead Lanthanum Zirconate Titanate Ceramics. J. Appl. Phys. 95, 2135-2140. doi:10.1063/1.1642285

Deng, G., Yin, Q., Ding, A., Zheng, X., Cheng, W., and Qiu, P. (2010). High Piezoelectric and Dielectric Properties of La-Doped $0.3 \mathrm{~Pb}\left(\mathrm{Zn}_{1 / 3} \mathrm{Nb}_{2 / 3}\right) \mathrm{O}_{3^{-}}$ $0.7 \mathrm{~Pb}($ ZrxTi1-x $) \mathrm{O}_{3}$ Ceramics Near Morphotropic Phase Boundary. J. Am. Ceram. Soc. 88, 2310-2314. doi:10.1111/j.1551-2916.2005.00391.x

Ding, G., Gao, F., Wu, G., and Bao, D. (2011). Bright Up-Conversion green Photoluminescence in $\mathrm{Ho}^{3+}-\mathrm{Yb}^{3+}$ Co-doped $\mathrm{B}_{\mathrm{i} 4} \mathrm{~T}_{\mathrm{i} 3} \mathrm{O}_{12}$ Ferroelectric Thin Films. J. Appl. Phys. 109, 123101. doi:10.1063/1.3596597

Du, J., Xu, Z., Chu, R., Hao, J., Li, W., Jiang, G., et al. (2017). Rare-earth Doped $\left(\mathrm{K}_{0.5} \mathrm{Na}_{0.5}\right) \mathrm{NbO}_{3}$ Multifunctional Ceramics. J. Mater. Sci. Mater. Electron. 28, 5288-5294. doi:10.1007/s10854-016-6186-6

Fan, G. F., Shi, M. B., Lu, W. Z., Wang, Y. Q., and Liang, F. (2014). Effects of $\mathrm{L}_{\mathrm{i} 2} \mathrm{CO}_{3}$ and $\mathrm{Sm}_{2} \mathrm{O}_{3}$ Additives on Low-Temperature Sintering and Piezoelectric Properties of PZN-PZT Ceramics. J. Eur. Ceram. Soc. 34, 23-28. doi:10.1016/j.jeurceramsoc.2013.07.028

Fang, Z., Jiang, X., Tian, X., Zheng, F., Cheng, M., Zhao, E., et al. (2021). Ultratransparent PMN-PT Electro-Optic Ceramics and its Application in Optical Communication. Adv. Opt. Mater. 2021, 2002139. doi:10.1002/ adom.202002139

Gao, F., Wu, G., Zhou, H., and Bao, D. (2009). Strong Upconversion Luminescence Properties of $\mathrm{Yb}^{3+}$ and $\mathrm{Er}^{3+}$ Codoped $\mathrm{B}_{\mathrm{i} 4} \mathrm{~T}_{\mathrm{i} 3} \mathrm{O}_{12}$ Ferroelectric Thin Films. J. Appl. Phys. 106, 126104-126698. doi:10.1063/1.3273477

Geng, Z., Li, K., Li, X., and Shi, D. (2017). Fabrication and Photoluminescence of Eu-Doped KNN-Based Transparent Ceramics. J. Mater. Sci. 52, 2285-2295. doi:10.1007/s10853-016-0521-4

Guo, J., Zhou, H., Fan, T., Zhao, B., Shang, X., Zhou, T., et al. (2020). Improving Electrical Properties and Toughening of PZT-Based Piezoelectric Ceramics for High-Power Applications via Doping Rare-Earth Oxides. J. Mater. Res. Tech. 9, 14254-14266. doi:10.1016/J.JMRT.2020.10.022

Guo, Q., Hou, L., Li, F., Xia, F., Wang, P., Hao, H., et al. (2019a). Investigation of Dielectric and Piezoelectric Properties in Aliovalent $\mathrm{Eu}^{3+}$-modified $\mathrm{Pb}\left(\mathrm{Mg}_{1 / 3}\right.$ $\left.\mathrm{Nb}_{2 / 3}\right) \mathrm{O}_{3}-\mathrm{PbTiO}_{3}$ Ceramics. J. Am. Ceram. Soc. 102, 7428-7435. doi:10.1111/ jace. 16653

Guo, Q., Li, F., Xia, F., Gao, X., Wang, P., Hao, H., et al. (2019b). High-Performance Sm-Doped $\mathrm{Pb}\left(\mathrm{Mg}_{1 / 3} \mathrm{Nb}_{2 / 3}\right) \mathrm{O}_{3}-\mathrm{PbZrO}_{3}-\mathrm{PbTiO}_{3}$-Based Piezoceramics. ACS Appl. Mater. Inter. 11, 43359-43367. doi:10.1021/acsami.9b15424

Hagemann, H.-J., and Hennings, D. (1981). Reversible Weight Change of Acceptor-Doped $\mathrm{BaTiO}_{3}$. J. Am. Ceram. Soc. 64, 590-594. doi:10.1111/ j.1151-2916.1981.tb10223.x

Hao, J., Xu, Z., Chu, R., Li, W., and Du, J. (2015). Bright Reddish-orange Emission and Good Piezoelectric Properties of $\mathrm{Sm}_{2} \mathrm{O}_{3}$-Modified $\left(\mathrm{K}_{0.5} \mathrm{Na}_{0.5}\right) \mathrm{NbO}_{3}$-Based lead-free Piezoelectric Ceramics. J. Appl. Phys. 117, 194104. doi:10.1063/ 1.4921451

He, C., Zhang, Y., Liang, S., Wang, J., Tong, W., Feng, X., et al. (2013). Electrical and Optical Properties of $\mathrm{Nd}^{3+}$-Doped $\mathrm{Na}_{0.5} \mathrm{Bi}_{0.5} \mathrm{TiO}_{3}$ Ferroelectric Single crystal. J. Phys. D. 46, 245104. doi:10.1088/0022-3727/46/24/245104

Hiruma, Y., Nagata, H., Hidaka, Y., and Tsukada, S. (2010). Depolarization Temperatures and Piezoelectric Properties of $\left(\mathrm{Bi}_{0.5} \mathrm{Na}_{0.5}\right) \mathrm{TiO}_{3}$ Ceramics and Single crystal. Ferroelectrics 404, 815-827. doi:10.1080/00150193.2010.482854

Inaguma, Y., Miyaguchi, A., Yoshida, M., and Katsumata, T. (2004). High-pressure Synthesis and Ferroelectric Properties in Perovskite-type $\mathrm{BiScO}_{3}-\mathrm{PbTiO}_{3}$ Solid Solution. J. Appl. Phys. 95, 231-235. doi:10.1063/1.1629394

Jaeger, R. E. (2010). Hot Pressing of Potassium-Sodium Niobates. J. Am. Ceram. Soc. 45, 209-213. doi:10.1111/j.1151-2916.1962.tb11127.x

Jiang, L., Wang, Z., Chen, Y., Chen, P., Luo, L., and Chen, H. (2018). Bright Up-Conversion Emission of $\mathrm{Er}^{3+}$-Doped lead-free Ferroelectric $\mathrm{Na}_{0.5} \mathrm{Bi}_{0.5} \mathrm{TiO}_{3}$ Single crystal. Mater. Lett. 210, 158-160. doi:10.1016/ j.matlet.2017.08.135

Jo, W., Daniels, J. E., Jones, J. L., Tan, X., Thomas, P. A., Damjanovic, D., et al. (2011). Evolving Morphotropic Phase Boundary in lead-free $\left(\mathrm{Bi}_{1 / 2} \mathrm{Na}_{1 / 2}\right) \mathrm{TiO}_{3}$ $\mathrm{BaTiO}_{3}$ Piezoceramics. J. Appl. Phys. 109, 14110. doi:10.1063/1.3530737

Kamzina, L. S., Wei, R., Li, G., Zeng, J., and Ding, A. (2010). Electro-optical Properties of PMN-xPT Compounds: Single Crystals and Transparent Ferroelectric Ceramic. Phys. Solid State 52, 2142-2146. doi:10.1134/ S1063783410100203

Khazanchi, R., Sharma, S., and Goel, T. C. (2005). Effect of Rare Earth Europium Substitution on the Microstructure, Dielectric, Ferroelectric and Pyroelectric
Properties of PZT Ceramics. J. Electroceram 14, 113-118. doi:10.1007/s10832005-0871-9

Kim, K. B., Hsu, D. K., Ahn, B., Kim, Y. G., and Barnard, D. J. (2010). Fabrication and Comparison of PMN-PT Single crystal, PZT and PZT-Based 1-3 Composite Ultrasonic Transducers for NDE Applications. Ultrasonics 50, 790-797. doi:10.1016/j.ultras.2010.04.001

Kim, K. T., Kim, C. I., Kang, D. H., and Shim, I. W. (2002). The Effect of Eu Substitution on the Ferroelectric Properties of $\mathrm{Bi}_{4} \mathrm{Ti}_{3} \mathrm{O}_{12}$ Thin Films Prepared by Metal-Organic Decomposition. Thin Solid Films 422, 230-234. doi:10.1016/ S0040-6090(02)00981-1

Kour, P., Kumar, P., Sinha, S. K., and Kar, M. (2015). Study of Dielectric and Impedance Spectroscopy of La Substituted Nanocrystalline $\mathrm{Pb}\left(\mathrm{Zr}_{0.52} \mathrm{Ti}_{.48}\right) \mathrm{O}_{3}$ Ceramics. J. Mater. Sci. Mater. Electron. 26, 1304-1310. doi:10.1007/s10854014-2538-2

Kour, P., Pradhan, S. K., Kumar, P., Sinha, S. K., and Kar, M. (2016). Enhanced Ferroelectric and Piezoelectric Properties in La-Modified PZT Ceramics. Appl. Phys. A-mater. 122, 1-7. doi:10.1007/s00339-016-0122-8

Kumari, M., Yadav, A., and Sarun, P. M. (2020). Systematic Investigation of Structural, Optical and Dielectric Properties of $0.5 \mathrm{Mol} \% \mathrm{Eu}: \mathrm{BaTiO}_{3}$ Ceramics. Mater. Today Proc. 42, 2214-7853. doi:10.1016/j.matpr.2020.03.337

Kuwata, J., Uchino, K., and Nomura, S. (1982). Dielectric and Piezoelectric Properties of $0.91 \mathrm{~Pb}\left(\mathrm{Zn}_{1 / 3} \mathrm{Nb}_{2 / 3}\right) \mathrm{O}_{3}-0.09 \mathrm{PbTiO}_{3}$ Single Crystals. Jpn. J. Appl. Phys. 21, 1298-1302. doi:10.1143/JJAP.21.1298

Lau, C. M., Xu, X. W., and Kwok, K. W. (2015). Photoluminescence, Ferroelectric, Dielectric and Piezoelectric Properties of Er-Doped BNT-BT Multifunctional Ceramics. Appl. Surf. Sci. 336, 314-320. doi:10.1016/j.apsusc.2014.12.105

Li, C., Xu, B., Lin, D., Zhang, S., and Li, F. (2020b). Atomic-scale Origin of Ultrahigh Piezoelectricity in Samarium-Doped PMN-PT Ceramics. Phys. Rev. B. 101, 140102. doi:10.1103/PhysRevB.101.140102

Li, F., Cabral, M. J., Xu, B., Cheng, Z., Dickey, E. C., Lebeau, J. M., et al. (2019b). Giant Piezoelectricity of Sm-Doped $\mathrm{Pb}\left(\mathrm{Mg}_{1 / 3} \mathrm{Nb}_{2 / 3}\right) \mathrm{O}_{3}-\mathrm{PbTiO}_{3}$ Single Crystals. Science 364, 264. doi:10.1126/science.aaw2781

Li, F., Lin, D., Chen, Z., Cheng, Z., Wang, J., Li, C. C., et al. (2018). Ultrahigh Piezoelectricity in Ferroelectric Ceramics by Design. Nat. Mater. 17, 349-424. doi:10.1038/s41563-018-0034-4

Li, H., Feng, C., and Yao, W. (2004). Some Effects of Different Additives on Dielectric and Piezoelectric Properties of $\left(\mathrm{Bi}_{1 / 2} \mathrm{Na}_{1 / 2}\right) \mathrm{TiO}_{3}-\mathrm{BaTiO}_{3}$ Morphotropic-Phase-Boundary Composition. Mater. Lett. 58, 1194-1198. doi:10.1016/j.matlet.2003.08.034

Li, H., Zhang, Y., Zhou, J., Zhang, X., Liu, H., and Fang, J. (2015a). Phase Structure and Electrical Properties of xPZN-(1-X)PZT Piezoceramics Near the Tetragonal/rhombohedral Phase Boundary. Ceram. Int. 41, 4822-4828. doi:10.1016/j.ceramint.2014.12.038

Li, Q., Wei, S., Jiang, Y., Ying, P., Qiang, C., Xi, Y., et al. (2009). “Effect of Y-Doping on the Piezoelectric Properties of $(1-\mathrm{x}) \mathrm{BiScO}_{3}-\mathrm{xPTiO}_{3}$ High-Temperature Piezoelectric Ceramics," in 2009 18th IEEE International Symposium on the Applications of Ferroelectrics (China: Xi'an), 1-4. doi:10.1109/ ISAF.2009.5307539

Li, W., Hao, J., Du, J., Fu, P., and Chu, R. (2020a). Electrical Properties and Luminescence Properties of $0.96\left(\mathrm{~K}_{0.48} \mathrm{Na}_{0.52}\right)\left(\mathrm{Nb}_{0.95} \mathrm{Sb}_{0.05}\right)-0.04 \mathrm{Bi}_{0.5}\left(\mathrm{Na}_{0.82} \mathrm{~K}_{0.18}\right)_{0.5} \mathrm{ZrO}_{3}-\mathrm{xSm}$ leadfree Ceramics. J. Adv. Ceram. 9, 72-82. doi:10.1007/s40145-019-0349-x

Li, X., Chen, C., Deng, H., Zhang, H., and Luo, H. (2015b). The Growth and Properties of lead-free Ferroelectric Single Crystals. Crystals 5, 172-192. doi:10.3390/cryst5020172

Li, Y., Xi, Z., Fang, P., Li, X., Long, W., He, A., et al. (2019c). Electric and Optical Properties of $\mathrm{Tm}^{3+} / \mathrm{Yb}^{3+}$ Co-doped PZN-9PT Crystals. J. Mater. Sci. Mater. Electron. 30, 3811-3819. doi:10.1007/s10854-019-00665-x

Li, Y. X., Yao, X., Wang, X. S., and Hao, Y. B. (2012). Studies of Dielectric Properties of Rare Earth (Dy, Tb, Eu) Doped Barium Titanate Sintered in Pure Nitrogen. Ceram. Int. 38, S29-S32. doi:10.1016/j.ceramint.2011.04.042

Li, Y., Zhao, J., Zhang, X., Jia, Q., and Hao, X. (2019a). Tuning the Ferroelectric, Dielectric and Photoluminescence Properties of $0.88\left(\mathrm{Na}_{0.5} \mathrm{Bi}_{0.5}\right) \mathrm{TiO}_{3}$ -

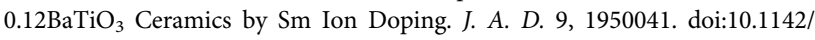
S2010135X19500413

Liu, L., Fan, H., Ke, S., and Chen, X. (2008). Effect of Sintering Temperature on the Structure and Properties of Cerium-Doped 0.94 $\left(\mathrm{Bi}_{0.5} \mathrm{Na}_{0.5}\right) \mathrm{TiO}_{3}-0.06 \mathrm{BaTiO}_{3}$ Piezoelectric Ceramics. J. Alloys Compd. 458, 504-508. doi:10.1016/ j.jallcom.2007.04.037 
Liu, L. (2015). Progress on the Fabrication of lead-free Textured Piezoelectric Ceramics: Perspectives over 25years. J. Mater. Sci-mater El. 26 (7), 4425-4437. doi:10.1007/s10854-015-2920-8

Liu, Z., Jiang, G., Wang, R., Chai, C., Zheng, L., Zhang, Z., et al. (2016). Temperature and Concentration Effects on Up-Conversion Photoluminescence Properties of $\mathrm{Ho}^{3+}$ and $\mathrm{Yb}^{3+}$ Co-doped $0.67 \mathrm{~Pb}\left(\mathrm{Mg}_{1 / 3} \mathrm{Nb}_{2 / 3}\right) \mathrm{O}_{3}-0.33 \mathrm{PbTiO}_{3}$ Multifunctional Ceramics. Ceram. Int. 45, 11309-11313. doi:10.1016/j.ceramint.2016.04.049

Lv, Z., Qin, Y., Zhang, Y., Fu, J., and Lu, C. (2019). Efficient Up-Conversion Photoluminescence in Transparent $\mathrm{Pr}^{3+} / \mathrm{Yb}^{3+}$ Co-doped $0.75 \mathrm{~Pb}\left(\mathrm{Mg}_{1 / 3} \mathrm{Nb}_{2 / 3}\right)$ $\mathrm{O}_{3}-0.25 \mathrm{PbTiO}_{3}$ Ferroelectric Ceramics. Ceram. Int. 45, 10924-10929. doi:10.1016/j.ceramint.2019.02.172

Ma, Z., Zhang, Y., Lu, C., Qin, Y., Lv, Z., and Lu, S. (2018). Synthesis and Properties of La-Doped PMN-PT Transparent Ferroelectric Ceramics. J. Mater. Sci-mater El. 29, 6985-6990. doi:10.1007/s10854-018-8685-0

Majumder, S. B., Dobal, P. S., Roy, B., Bhaskar, S., Katiyar, R. S., and Bhalla, A. (2001). Effect of Rare Earth Doping on Sol-Gel Derived PZT Thin Films. Ferroelectrics Lett. 28, 85-92. doi:10.1080/07315170108202952

Morrison, F. D., Coats, A. M., Sinclair, D. C., and West, A. R. (2001). Charge Compensation Mechanisms in La-Doped $\mathrm{BaTiO}_{3}$. J. Electroceramics 6, 219-232. doi:10.1023/A:1011400630449

Nakaki, H., Uchida, H., Okamoto, S., Yokoyama, S., Funakubo, H., and Koda, S. (2004). Improvement of Ferroelectric Properties of lead Zirconate Titanate Thin Films by Ion-Substitution Using Rare-Earth Cations. Mrs Proc. 830, D3. doi:10.1557/PROC-830-D3.3

Panda, P. K. (2009). Review: Environmental Friendly lead-free Piezoelectric Materials. J. Mater. Sci. 44, 5049-5062. doi:10.1007/s10853-009-3643-0

Pandey, S. K., Kumar, S., Chatterjee, S. N., Kumar, U., Prakash, C., Chatterjee, R., et al. (2007). Growth and Characterization of $\mathrm{Sm}^{3+}$-Substituted PZT Thin Films. Physica B 388, 404-411. doi:10.1016/j.physb.2006.06.167

Pandey, S. K., Thakur, O. P., Bhattacharya, D. K., Prakash, C., and Chatterjee, R. (2009). Structural and Electrical Properties of $\mathrm{Sm}^{3+}$ Substituted PZT Ceramics. J. Alloys Compd. 468, 356-359. doi:10.1016/j.jallcom.2008.01.006

Peng, F., Xu, Z., Chu, R., Wei, L., Zang, G., and Hao, J. (2010c). Piezoelectric, Ferroelectric and Dielectric Properties of $\mathrm{La}_{2} \mathrm{O}_{3}$-Doped $\left(\mathrm{Bi}_{0.5} \mathrm{Na}_{0.5}\right)_{0.94} \mathrm{Ba}_{0.06} \mathrm{TiO}_{3}$ lead-free Ceramics lead-free Ceramics. Mater. Des. 31, 706-801. doi:10.1016/j.matdes.2009.07.056

Peng, F., Xu, Z., Chu, R., Wei, L., Zang, G., and Hao, J. (2010b). Piezoelectric, Ferroelectric and Dielectric Properties of $\mathrm{Nd}_{2} \mathrm{O}_{3}$-Doped $\left(\mathrm{Bi}_{0.5} \mathrm{Na}_{0.5}\right)_{0.94} \mathrm{Ba}_{0.06} \mathrm{TiO}_{3}$ lead-free Ceramics. Mater. Sci. Eng. B. 167, 161-166. doi:10.1016/j.mseb.2010.01.057

Peng, F., Xu, Z., Chu, R., Wei, L., Zang, G., and Hao, J. (2010a). Piezoelectric, Ferroelectric and Dielectric Properties of $\mathrm{Sm}_{2} \mathrm{O}_{3}$-Doped $\left(\mathrm{Bi}_{0.5} \mathrm{Na}_{0.5}\right)_{0.94} \mathrm{Ba}_{0.06} \mathrm{TiO}_{3}$ lead-free Ceramics. Mater. Sci. Eng. B. 124, 1065-1070. doi:10.1016/j.matchemphys.2010.08.033

Peng, G., Zheng, D., Hu, S., Zhao, H., and Cheng, C. (2016). Effects of Rare-Earth $\mathrm{Sm}_{2} \mathrm{O}_{3}$ Addition on Relaxation Behavior and Electric Properties of 0.5PNN-0.5PZT Ceramics. J. Mater. Sci. Mater. Electron. 27, 5509-5516. doi:10.1007/s10854-016-4577-3

Perumal, R. N., Sadhasivam, S., and Athikesavan, V. (2019). Structural, Dielectric, Ac Conductivity, Piezoelectric and Impedance Spectroscopy Studies on $\mathrm{PbZr}_{0.52} \mathrm{Ti}_{0.48} \mathrm{O}_{3}: \mathrm{Re}^{3+}\left(\mathrm{Re}^{3+}: \mathrm{La}^{3+}, \mathrm{Nd}^{3+}\right.$ and $\left.\mathrm{Dy}^{3+}\right)$ Ceramics. Results Phys. 15, 102729. doi:10.1016/j.rinp.2019.102729

Pieter, D. (2017). Charge Transfer Bands in Optical Materials and Related Defect Level Location. Opt. Mater. 69, 8-22. doi:10.1016/j.optmat.2017.03.061

Pieter, D. (2013). Lanthanide 4f-Electron Binding Energies and the Nephelauxetic Effect in Wide Band gap Compounds. J. Lumin. 136, 122-129. doi:10.1016/ j.jlumin.2012.11.030

Politova, E. D., Egorova, B. V., Kaleva, G. M., Mosunov, A. V., and Zeng, J. (2011). Phase Transitions and the Dielectric and Piezoelectric Properties of Ceramic Solid Solutions Based on $\mathrm{BiScO}_{3}-\mathrm{PbTiO}_{3}$. Bull. Russ. Acad. Sci. Phys. 75, 1166-1169. doi:10.3103/S1062873811050418

Qiu, W., and Hng, H. H. (2002). Effects of Dopants on the Microstructure and Properties of PZT Ceramics. Mater. Chem. Phys. 75, 151-156. doi:10.1016/ S0254-0584(02)00045-7

Rajan, K. K., Shanthi, M., Chang, W. S., Jin, J., and Lim, L. C. (2007). Dielectric and Piezoelectric Properties of $\left[\begin{array}{lll}0 & 0 & 1\end{array}\right]$ and $\left[\begin{array}{lll}0 & 1 & 1\end{array}\right]$-poled Relaxor Ferroelectric
PZN-PT and PMN-PT Single Crystals. Sensor Actuat A-Phys. 133, 110-116. doi:10.1016/j.sna.2006.03.036

Rath, M., Miryala, M., Murakami, M., and Rao, M. S. R. (2019). Controlled Piezotronic Properties on Recoverable Energy Storage Density in Rare-Earth Ions Doped Epitaxial PZT Thin Films. J. Phys. D. 52, 304001. doi:10.1088/13616463/ab1b08

Ruan, K., Chen, X., Liang, T., Wu, G., and Bao, D. (2008). Photoluminescence and Electrical Properties of Highly Transparent $(\mathrm{Bi}, \mathrm{Eu})_{4} \mathrm{Ti}_{3} \mathrm{O}_{12}$ Ferroelectric Thin Films on Indium-Tin-Oxide-Coated Glass Substrates. J. Appl. Phys. 103, 627. doi:10.1063/1.2903928

Saito, Y., Takao, H., Tani, T., Nonoyama, T., Takatori, K., Homma, T., et al. (2004). Lead-free Piezoceramics. Nature 432, 84-87. doi:10.1038/nature03028

Samad, R., Rather, M., Asokan, K., and Want, B. (2017). Structural, Dielectric and Ferroelectric Properties of Rare Earth Substituted lead Zirconate Titanate. J. Mater. Sci-mater El. 29, 4226-4237. doi:10.1007/s10854-017-8368-2

Shannigrahi, R. S., Tay, F. E. H., Yao, K., and Choudhary, R. N. P. (2004). Effect of Rare Earth (La, Nd, Sm, Eu, Gd, Dy, Er and $\mathrm{Yb}$ ) Ion Substitutions on the Microstructural and Electrical Properties of Sol-Gel Grown PZT Ceramics Science Direct. J. Eur. Ceram. Soc. 24, 163-170. doi:10.1016/S0955-2219(03) 00316-9

Shrout, T. R., and Zhang, S. J. (2007). Lead-free Piezoelectric Ceramics: Alternatives for PZT?. J. Electroceram 19, 113-126. doi:10.1007/s10832-0079047-0

Singh, D. J., Ghita, M., Fornari, M., and Halilov, S. V. (2011). Role of A-Site and B-Site Ions in Perovskite Ferroelectricity. Ferroelectrics 338, 73-79. doi:10.1080/ 00150190600732694

Singh, N., Shyam, R., Upadhyay, N. K., and Dhar, A. (2015). Development of RareEarth Free Mn-Al Permanent Magnet Employing Powder Metallurgy Route. IOP Conf. Ser. Mater. Sci. Eng. 73, 012042. doi:10.1088/1757-899X/73/1/012042

Steudel, F., Loos, S., Ahrens, B., and Schweizer, S. (2015). Quantum Efficiency and Energy Transfer Processes in Rare-Earth Doped Borate Glass for Solid-State Lighting. J. Lumin. 170, 157-162. doi:10.1016/j.jlumin.2015.07.032

Sun, H., Peng, D., Wang, X., Tang, M., Zhang, Q., and Yao, X. (2012). Green and Red Emission for $\left(\mathrm{K}_{0.5} \mathrm{Na}_{0.5}\right) \mathrm{NbO}_{3}$ : Pr Ceramics. J. Appl. Phys. 111, 2087. doi:10.1063/1.3686193

Sun, H., Peng, D., Wang, X., Tang, M., Zhang, Q., and Yao, X. (2011). Strong Red Emission in Pr Doped $\left(\mathrm{Bi}_{0.5} \mathrm{Na}_{0.5}\right) \mathrm{TiO}_{3}$ Ferroelectric Ceramics. J. Appl. Phys. 110, 2087. doi:10.1063/1.3606425

Sun, H. Q., Wang, X. S., and Yao, X. (2010). Structure and Electric Properties of Sm Doped $\mathrm{BaTiO}_{3}$ Ceramics. Ferroelectrics 404, 99-104. doi:10.1080/ 00150193.2010.482459

Sun, H., Zhang, Q., Wang, X., and Mu, G. (2014). Green and Red Up-Conversion Luminescence of $\mathrm{Er}^{3+}$-Doped $\mathrm{K}_{0.5} \mathrm{Na}_{0.5} \mathrm{NbO}_{3}$ Ceramics. Ceram. Int. 40, 2581-2584. doi:10.1016/j.ceramint.2013.10.089

Sun, L. N., Zhang, H. J., Peng, C. Y., Yu, J. B., Meng, Q. G., Fu, L. S., et al. (2006). Covalent Linking of Near-Infrared Luminescent Ternary Lanthanide $(\operatorname{Er}(3+)$, $\mathrm{Nd}(3+), \mathrm{Yb}(3+))$ Complexes on Functionalized Mesoporous MCM-41 and SBA-15. J. Phys. Chem. B 110, 7249-7258. doi:10.1021/jp060395u

Tsonev, L. (2008). Luminescent Activation of Planar Optical Waveguides in $\mathrm{LiNbO}_{3}$ with Rare Earth Ions $\mathrm{Ln}^{3+}$ a Review. Opt. Mater. 30, 892-899. doi:10.1016/j.optmat.2007.03.011

Uchino, K. (1995). Electro-optic Ceramics and Their Display Applications. Ceram. Int. 21, 309-315. doi:10.1016/0272-8842(95)96202-Z

Vittayakorn, N., Rujijanagul, G., Tan, X., He, H., Marquardt, M. A., and Cann, D. P. (2006). Dielectric Properties and Morphotropic Phase Boundaries in the $\mathrm{xPb}\left(\mathrm{Zn}_{1 / 3} \mathrm{Nb}_{2 / 3}\right) \mathrm{O}_{3}-(1-\mathrm{x}) \mathrm{Pb}\left(\mathrm{Zr}_{0.5} \mathrm{Ti}_{0.5}\right) \mathrm{O}_{3} \quad$ Pseudo-binary System. J. Electroceramic 16, 141-149. doi:10.1007/s10832-006-4927-2

Wang, N., Sun, Q., Ma, W., Yong, Z., and Liu, H. (2012). Investigation of La-Doped $0.25 \mathrm{~Pb}\left(\mathrm{Zn}_{1 / 3} \mathrm{Nb}_{2 / 3}\right) \mathrm{O}_{3}-0.75 \mathrm{~Pb}\left(\mathrm{Zr}_{\mathrm{x}} \mathrm{Ti}_{1-\mathrm{x}}\right) \mathrm{O}_{3}$ Ceramics Near Morphotropic Phase Boundary. J. Electroceramics 28, 15-19. doi:10.1007/s10832-011-9672-5

Wei, R., Li, G., Zeng, J., Bian, J., Kamzina, L. S., Zeng, H., et al. (2010). Large Electro-Optic Effect in La-Doped $0.75 \mathrm{~Pb}\left(\mathrm{Mg}_{1 / 3} \mathrm{Nb}_{2 / 3}\right) \mathrm{O}_{3}-0.25 \mathrm{PbTiO}_{3}$ Transparent Ceramic by Two-Stage Sintering. Int. J. Appl. Ceram. Tec 93, 2128-2131. doi:10.1111/j.1551-2916.2010.03675.x

Wei, Z., Huang, Y., Tsuboi, T., Nakai, Y., Zeng, J., and Li, G. (2012a). Optical Characteristics of $\mathrm{Er}^{3+}$-Doped PMN-PT Transparent Ceramics. Ceram. Int. 38, 3397-3402. doi:10.1016/j.ceramint.2011.12.051 
Wei, Z., Tsuboi, T., Nakai, Y., Huang, Y., Zeng, J., and Li, G. (2012b). The Synthesis of $\mathrm{Er}^{3+}$-Doped PMN-PT Transparent Ceramic and its Infrared Luminescence. Mater. Lett. 68, 57-59. doi:10.1016/j.matlet.2011.10.034

Wu, X., Chi, M. L., and Kwok, K. W. (2015a). Photoluminescence Properties of Er/ Pr-Doped $\mathrm{K}_{0.5} \mathrm{Na}_{0.5} \mathrm{NbO}_{3}$ Ferroelectric Ceramics. J. Am. Ceram. Soc. 98, 2139-2145. doi:10.1111/jace.13605

Wu, X., Chung, T. H., and Kwok, K. W. (2015b). Enhanced Visible and Mid-IR Emissions in $\mathrm{Er} / \mathrm{Yb}$-Codoped $\mathrm{K}_{0.5} \mathrm{Na}_{0 .} \mathrm{NbO}_{3}$ Ferroelectric Ceramics. Ceram. Int. 41, 14041-14048. doi:10.1016/j.ceramint.2015.07.018

Wu, X., Kwok, K. W., and Li, F. L. (2013). Up-conversion Fluorescence Studies of Sol-Gel Derived Er-Doped KNN Ceramics. J. Alloys Compd. 580, 88-92. doi:10.1016/j.jallcom.2013.05.096

Wu, X., Lu, S., and Kwok, K. W. (2017). Photoluminescence, Electro-Optic Response and Piezoelectric Properties in Pressureless-Sintered Er-Doped KNN-Based Transparent Ceramics. J. Alloys Compd. 695, 3573-3578. doi:10.1016/j.jallcom.2016.11.409

Xi, Z., Han, A., Fang, P., Li, X., and Long, W. (2016a). Electrical Properties and UpConversion Luminescence of the $\mathrm{Er}^{3+}$-Modified PZN-9PT Crystals. Int. J. Mater. Res. 31, 3044-3049. doi:10.1557/jmr.2016.311

Xi, Z., Han, A., Fang, P., Long, W., Li, X., and Bu, Q. (2016b). Structural and Electrical Properties of $\mathrm{Ho}^{3+}$-Modified $\mathrm{Pb}\left(\mathrm{Zn}_{1 / 3} \mathrm{Nb}_{2 / 3}\right) \mathrm{O}_{3}-9 \mathrm{PbTiO}_{3}$ Single Crystals. Mater. Sci. Mater. Electron. 27, 4223-4229. doi:10.1007/s10854016-4286-y

Xie, D., Zhang, Z., Ren, T., Liu, T., and Liu, L. (2006). Properties of NeodymiumDoped $\mathrm{Bi}_{4} \mathrm{Ti}_{3} \mathrm{O}_{12}$ Thin Films for Ferroelectric Random Access Memory. Integrated Ferroelectrics 84, 67-73. doi:10.1080/10584580601085230

Xu, J., Lu, Q., Lin, C., Zheng, X., Lin, T., and Wu, X. (2020). Enhanced Ferro-/ piezoelectric Properties of Tape-Casting-Derived $\mathrm{Er}^{3+}$-doped $\mathrm{Ba}_{0.85} \mathrm{Ca}_{0.15} \mathrm{Ti}_{0.9} \mathrm{Zr}_{0.1} \mathrm{O}_{3}$ Optoelectronic Thick Films. J. Adv. Ceram. 9, 693-702. doi:10.1007/s40145-020-0405-6

Yang, D., Yang, Z., Zhang, X., Wei, L., Chao, X., and Yang, Z. (2017). High Transmittance in lead-free Lanthanum Modified Potassium-Sodium Niobate Ceramics. J. Alloys Compd. 716, 21-29. doi:10.1016/ j.jallcom.2017.04.236

Yao, Z. H., Liu, H. X., Li, Y. Q., Cao, Y. Q., and Hao, H. (2010). Morphotropic Phase Boundary of $\left.\left(\mathrm{Bi}_{0.9} \mathrm{La}_{0.1}\right) \mathrm{ScO}_{3}-\mathrm{PbTi}\right) \mathrm{O}_{3}$ Piezoelectric Ceramics for HighTemperature Application. Ferroelectrics 409, 21-26. doi:10.1080/ 00150193.2010.485886

Yu, Y. J., Chan, H. L. W., Wang, F. P., and Zhao, L. C. (2003). Effects of Rare Earth Eu Doping on Ferroelectric Properties of $\mathrm{PbZr}_{0.52} \mathrm{Ti}_{0.48} \mathrm{O}_{3}$ Thin Films by Sol-Gel Methods. Microelectron Eng. 66, 0167-9317. doi:10.1016/S0167-9317(02)00991-7

Zeng, X., He, X., Cheng, W., Qiu, P., and Xia, B. (2014). Effect of Dy Substitution on Ferroelectric, Optical and Electro-Optic Properties of Transparent $\mathrm{Pb}_{0.90} \mathrm{La}_{0.10}\left(\mathrm{Zr}_{0.65} \mathrm{Ti}_{0.35}\right) \mathrm{O}_{3}$ Ceramics. Ceram. Int. 40, 6197-6202. doi:10.1016/j.ceramint.2013.11.074

Zhai, Y., Feng, Y., Du, J., Xue, J., Shen, J., Lu, Y., et al. (2019). The Impedance, Dielectric and Piezoelectric Properties of $\mathrm{Tb}_{4} \mathrm{O}_{7}$ and $\mathrm{Tm}_{2} \mathrm{O}_{3}$ Doped KNN Ceramics. Mater. Sci. Mater. Electron. 30, 4352-4358. doi:10.1007/s10854-01900748-9

Zhang, H., Zhao, X., Hao, D., Chao, C., Di, L., Li, X., et al. (2014c). Photoluminescence and Electrical Properties of Eu-Doped $\left(\mathrm{Na}_{0.5} \mathrm{Bi}_{0.5}\right) \mathrm{TiO}_{3}$ Ferroelectric Single Crystals. Appl. Phys. A-mater. 114, 357-361. doi:10.1007/ s00339-013-8176-3

Zhang, J. R., Zhang, Y. C., Lu, C. J., Ye, W. N., and Su, J. (2014a). Effect of LaDoping Content on the Dielectric and Ferroelectric Properties of $0.88 \mathrm{~Pb}\left(\mathrm{Mg}_{1 /}\right.$ $\left.{ }_{3} \mathrm{Nb}_{2 / 3}\right) \mathrm{O}_{3}-0.12 \mathrm{PbTiO}_{3}$ Ceramics. J. Mater. Sci. Mater. Electron. 25, 653-658. doi:10.1007/s10854-013-1688-y

Zhang, J. W., Zou, Y. K., Chen, Q., Zhang, R., Li, K. K., Jiang, H., et al. (2006). Optical Amplification in $\mathrm{Nd}^{3+}$ Doped Electro-Optic Lanthanum lead Zirconate Titanate Ceramics. Appl. Phys. Lett. 89, 411-426. doi:10.1063/1.2336216

Zhang, K., Li, L., Wang, M., and Luo, W. (2020a). Charge Compensation in Rare Earth Doped $\mathrm{BaTiO}_{3}$-Based Ceramics Sintered in Reducing Atmosphere. Ceram. Int. 46, 25881-25887. doi:10.1016/j.ceramint.2020.07.072

Zhang, Q., Chen, J., and Che, M. (2020b). Dielectric Properties of Barium Titanium Ceramics Doped by Lanthanum Oxide. Ferroelectrics 566, 30-41. doi:10.1080/ 00150193.2020 .1762427

Zhang, Q., Sun, H., Wang, X., and Zhang, T. (2014b). Highly Efficient orange Emission $\left(\mathrm{K}_{0.5} \mathrm{Na}_{0.5}\right) \mathrm{NbO}_{3}$ : $\mathrm{Sm}^{3+}$ lead Free Piezoceramics. Mater. Lett. 117, 283-285. doi:10.1016/j.matlet.2013.12.026

Zhang, R., Wang, X., Zhang, S., Yang, Z., and Zou, H. (2021). Effect of Dy Doping on the crystal Orientation, Microstructure, and Electrical Properties of PDZT Thin Films Prepared by Sol-Gel Method. J. Mater. Sci. Mater. Electron. 32, 3612-3620. doi:10.1007/s10854-020-05108-6

Zhang, S., Alberta, E. F., Eitel, R. E., Randall, C. A., and Shrout, T. R. (2005). Elastic, Piezoelectric, and Dielectric Characterization of Modified $\mathrm{BiScO}_{3}-\mathrm{PbTiO}_{3}$ Ceramics. IEEE Trans. Ultrason. Ferroelectrics Frequency Control. 52, 2131-2139. doi:10.1109/TUFFC.2005.1561684

Zhang, S. T., Zhang, X. J., Cheng, H. W., Chen, Y. F., Liu, Z. G., Ming, N. B., et al. (2003). Enhanced Electrical Properties of C-axis Epitaxial Nd-Substituted $\mathrm{Bi}_{4} \mathrm{Ti}_{3} \mathrm{O}_{12}$ Thin Films. Appl. Phys. Lett. 83, 4378-4380. doi:10.1063/1.1629372

Zhao, H., Zhang, K., Xu, L., Sun, F., Chen, X., Li, K. K., et al. (2014). Optical Amplification in Disordered Electro-Optic $\mathrm{Tm}^{3+}$ and $\mathrm{Ho}^{3+}$ Co-doped Lanthanum-Modified lead Zirconate Titanate Ceramics and Study of Spectroscopy and Communication between Cations. J. Appl. Phys. 115, 397-2971. doi:10.1063/1.4866000

Zheng, M., Hou, Y., Zhu, M., Zhang, M., and Yan, H. (2014). Shift of Morphotropic Phase Boundary in High-Performance fine-grained PZN-PZT Ceramics. J. Eur. Ceram. Soc. 34, 2275-2283. doi:10.1016/j.jeurceramsoc.2014.02.041

Zheng, T., Wu, J., Xiao, D., and Zhu, J. (2018). Recent Development in lead-free Perovskite Piezoelectric Bulk Materials. Prog. Mater. Sci. 98, 552-624. doi:10.1016/j.pmatsci.2018.06.002

Zhou, J., Ma, Q., Wang, P., Cheng, L., and Liu, S. (2014). Influence of Rare-Earth $\mathrm{Nd}$, Dy, and Ho Doping on Structural and Electrical Properties of $\left(\mathrm{Na}_{0.53} \mathrm{~K}_{0.47}\right)$ $0.942 \mathrm{Li}_{0.058} \mathrm{NbO}_{3}$ Based lead-free Piezoceramics. Ceram. Int. 40, 2451-2459. doi:10.1016/j.ceramint.2013.08.020

Zhou, Z., Tang, Z. L., Zhang, Z. T., and Wlodarski, W. (2001). Perovskite Oxide of PTCR Ceramics as Chemical Sensors. Sens. Actuators B Chem. 77, 22-26. doi:10.1016/S0925-4005(01)00667-0

Conflict of Interest: The authors declare that the research was conducted in the absence of any commercial or financial relationships that could be construed as a potential conflict of interest.

Copyright $\odot 2021$ Chen, Zhang, Peng, Yuan and Ji. This is an open-access article distributed under the terms of the Creative Commons Attribution License (CC BY). The use, distribution or reproduction in other forums is permitted, provided the original author(s) and the copyright owner(s) are credited and that the original publication in this journal is cited, in accordance with accepted academic practice. No use, distribution or reproduction is permitted which does not comply with these terms. 